\title{
Graphene-Based Electrodes in a Vanadium Redox Flow Battery Produced by Rapid Low-Pressure Combined Gas Plasma Treatments
}

\author{
Sebastiano Bellani,*, Leyla Najafi, Mirko Prato, Reinier Oropesa-Nuñez, Beatriz Martín-García, \\ Luca Gagliani, Elisa Mantero, Luigi Marasco, Gabriele Bianca, Marilena I. Zappia, Cansunur Demirci, \\ Silvia Olivotto, Giacomo Mariucci, Vittorio Pellegrini, Massimo Schiavetti, and Francesco Bonaccorso*
}

ABSTRACT: The development of high-power density vanadium redox flow batteries (VRFBs) with high energy efficiencies (EEs) is crucial for the widespread dissemination of this energy storage technology. In this work, we report the production of novel hierarchical carbonaceous nanomaterials for VRFB electrodes with high catalytic activity toward the vanadium redox reactions $\left(\mathrm{VO}^{2+} / \mathrm{VO}_{2}{ }^{+}\right.$and $\left.\mathrm{V}^{2+} / \mathrm{V}^{3+}\right)$. The electrode materials are produced through a rapid (minute timescale) low-pressure combined gas plasma treatment of graphite felts (GFs) in an inductively coupled radio frequency reactor. By systematically studying the effects of either pure gases $\left(\mathrm{O}_{2}\right.$ and $\mathrm{N}_{2}$ ) or their combination at different gas plasma pressures, the electrodes are optimized to reduce their kinetic polarization for the VRFB redox reactions. To further enhance the catalytic surface area of the electrodes, single-/fewlayer graphene, produced by highly scalable wet-jet milling exfoliation of graphite, is incorporated into the GFs through an infiltration method in the presence of a polymeric binder. Depending on the thickness of the proton-exchange membrane (Nafion 115 or Nafion XL), our optimized VRFB configurations can efficiently operate within a wide range of charge/discharge current densities, exhibiting energy efficiencies up to $93.9 \%, 90.8 \%, 88.3 \%, 85.6 \%, 77.6 \%$, and $69.5 \%$ at $25,50,75,100,200$, and $300 \mathrm{~mA} \mathrm{~cm}^{-2}$, respectively. Our technology is cost-competitive when compared to commercial ones (additional electrode costs $<100 € \mathrm{~m}^{-2}$ ) and shows EEs rivalling the record-high values reported for efficient systems to date. Our work remarks on the importance to study modified plasma conditions or plasma methods alternative to those reported previously (e.g., atmospheric plasmas) to improve further the electrode performances of the current VRFB systems.

\section{INTRODUCTION}

Advanced large-scale energy storage systems (ESSs) are needed to meet the worldwide energy demand by exploiting renewable energy resources, ${ }^{1-5}$ such as solar ${ }^{6-8}$ and wind energies. ${ }^{9-11}$ In fact, the intermittency and the instability of renewable power outputs have to be efficiently counterbalanced by the capability of ESSs to ensure a safe and reliable power supply continuously or on-demand. ${ }^{12,13}$ In this context, redox-flow batteries (RFBs) ${ }^{14-20}$ represent a promising stationary ESS technology because of their outstanding storage capability and output power $^{21-29}$ combined with prospective low costs, ${ }^{30-38}$ easy scalability, ${ }^{39,32,40}$ long lifetime, ${ }^{41,42}$ low maintenance, ${ }^{43,44}$ safety $^{44,45}$ and environmental friendliness. ${ }^{44,45}$ Contrary to case-enclosed batteries, RFBs store the energy in the redoxactive material-based electrolytes, filling external reservoirs. ${ }^{14-18}$ The electrolytes flow from the reservoirs to the electrode surfaces, where the redox reactions occur rapidly compared to those in metal (e.g., Li, Na, K, etc.)-ion batteries. ${ }^{46,46,47}$ As a result, the overall RFB capacities can be adapted to industrialscale applications by enlarging the volume of the reservoirs

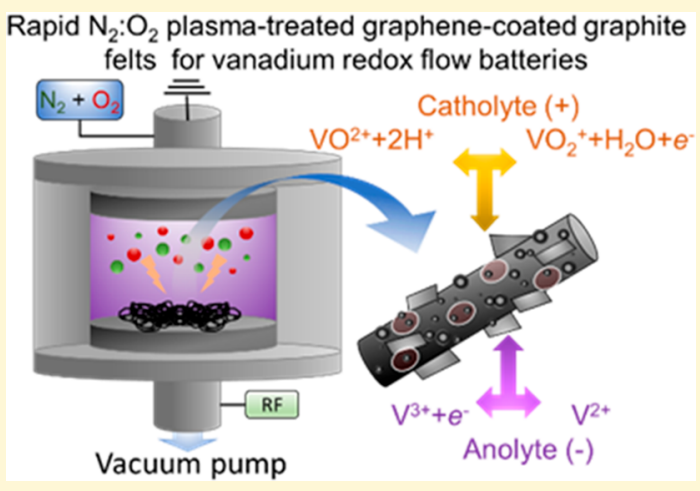

independently by the power characteristics, which are defined by the size and number of cells in a module unit. ${ }^{48-50,47}$ The energy density of a RFB is usually determined by three factors: (1) the concentration of the redox-active materials; ${ }^{23,51-53}$ (2) the number of transferred electrons in the redox reactions; ${ }^{54}$ and (3) the RFB voltage. ${ }^{5,56}$ Among the RFBs, aqueous vanadium (V) redox flow batteries (VRFBs) ${ }^{57-60}$ have been commercialized $^{61-64}$ thanks to their relevant energy and power performance coupled with the use of V-based species in both half-cells. The latter feature intrinsically diminishes the cross-contamination of active components, ${ }^{65-67}$ eliminating the need of extensive separation techniques in order to recover the battery components at the end of the battery life, consequently lowering

Received: March 3, 2021

Revised: April 26, 2021

Published: May 26, 2021

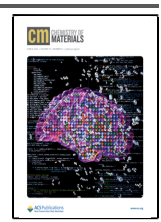


the costs of practical plants. ${ }^{64,67}$ Vanadium also has the advantage of being recovered from industrial waste products, such as fly ash ${ }^{68,69}$ or mine tailings, ${ }^{70,71}$ cleaning up the environment. As a striking example, the "World's largest battery", a 200-MW, 800-MWh storage station based on VRFBs, manufactured by affiliated Rongke Power and UniEnergy Technologies (UET), is being built in the Dalian peninsula in northern China. ${ }^{72}$

In order to encourage the market take-up of the VRFB technologies, researchers are struggling with improving the power density performance while retaining high energy efficiencies (EEs). ${ }^{29,60,73-77}$ In fact, efficient high-power density operation can reduce the cell stack size, ${ }^{74,75,78}$ consequently decreasing the capital cost of a VRFB plant. ${ }^{74,75,73}$ Therefore, the development of feasible electrode materials with (1) high electrical conductivity, ${ }^{79-81}$ which limits the ohmic polarization; ${ }^{79-81}$ (2) high surface area with abundant catalytic sites for VRFB redox reactions (i.e., $\mathrm{VO}^{2+} / \mathrm{VO}_{2}{ }^{+}$and $\mathrm{V}^{2+} / \mathrm{V}^{3+}$ at the positive and negative electrodes, respectively); ${ }^{78-81}$ and (3) hydrophilicity, which provides an optimal electrochemical accessibility of the redox-active materials to the electrode surface, is a research hotspot. ${ }^{82}$ Nowadays, graphitic materials, in particular graphite felts (GFs), are regularly used as electrodes for commercial VRFBs ${ }^{83-87}$ due to their low-cost manufacturing, ${ }^{88}$ excellent electrical conductivity, ${ }^{89,90}$ electrochemical stability, ${ }^{89,85}$ and optimal hydraulic permeability. ${ }^{89,89,91}$ However, their insufficient electrochemical activity toward the VRFB redox reactions ${ }^{92,93}$ and low surface area $\left(<1 \mathrm{~m}^{2} \mathrm{~g}^{-1}\right)^{89,90}$ severely limit the voltage efficiency (VE) and, thus, the overall EE of the VRFBs. ${ }^{64,87,94}$ Furthermore, the hydrophobic nature of graphitic materials may hamper the electrolyte access to the electrode surface in the VRFBs. ${ }^{84,92}$ Although the specific surface area can be simply increased by increasing the number of carbon fibers with reduced diameters, this strategy inevitably limits the hydraulic permeability of the electrode, increasing the energy required for adequate electrolyte pumping. To circumvent the trade-off between the specific surface area and the hydraulic permeability, several chemical/physical ${ }^{76,84,95-100}$ and thermal treatments ${ }^{29,92,101-103}$ have been reported to enhance the native electrochemical performance of the GFs. These approaches aim to introduce catalytic sites, such as chalcogen $\left(\mathrm{O}^{92,95,99,100,104-109}\right.$ and $\left.\mathrm{S}^{110}\right), \mathrm{N}^{101,105,111-113} \mathrm{P},{ }^{114}$ and halogen ${ }^{114}$ functional groups, and/or to increase the specific surface area by etching processes. ${ }^{97,115-120}$ However, the most effective processes often require a prolonged processing time, toxic, corrosive, and expensive chemicals, and/or a high temperature. $^{64,83}$ Therefore, alternative methods are pursued to scale-up the manufacturing of highly efficient electrodes for commercial applications. ${ }^{64,83}$ The incorporation of metals $\left(\mathrm{Ir},{ }^{121,122} \mathrm{Au},{ }^{123} \mathrm{Pd},{ }^{123} \mathrm{Pt},{ }^{123,124} \mathrm{Cu}^{125}\right.$ and $\left.\mathrm{Bi}^{29,126-128}\right)$, metal oxides $\left(\mathrm{Nb}_{2} \mathrm{O}_{5},{ }^{129} \mathrm{CeO}_{2}{ }^{130,131} \mathrm{ZrO}_{2}{ }^{132,133} \mathrm{PbO}_{2}{ }^{134}\right.$ $\mathrm{Mn}_{3} \mathrm{O}_{4}{ }^{135} \mathrm{MoO}_{2},{ }^{136} \mathrm{Ta}_{2} \mathrm{O}_{5}{ }^{137} \mathrm{Nd}_{2} \mathrm{O}_{3}{ }^{138} \mathrm{NiO},{ }^{139}$ and $\mathrm{WO}_{3}{ }^{140}$ ) and inorganic pigments (e.g., Prussian blue) ${ }^{141}$ into GFs as electrocatalysts has been also proposed. Nevertheless, the metals catalyze water splitting reactions, ${ }^{121-124}$ while metal oxides show a limited electrical conductivity. $^{129,130,132,134-136,140}$ To bypass such drawbacks, carbonbased electrocatalytic nanomaterials, ${ }^{142}$ including graphene derivatives, ${ }^{143-155}$ carbon nanotubes, ${ }^{156-166}$ carbon nanospheres/dots, ${ }^{167-171}$ carbon black, ${ }^{172}$ carbon nanosheets, ${ }^{173}$ and carbon nanorods ${ }^{174}$ have been used to decorate the GF surface. Although VRFBs with high rate capability (EE $\geq 80 \%$ at charge/discharge (CD), current densities $\geq 100 \mathrm{~mA}$ $\left.\mathrm{cm}^{-2}\right)^{29,143-145,147,164,170,171,174}$ have been successfully reported, either the cost or the long processing time of nanomaterial production and deposition hinder their practical implementation. ${ }^{64,83}$ The detachment of nanomaterials can also negatively affect the long-term operation electrode performance, while contaminating the electrolyte. ${ }^{64,83}$

In this work, we report a rapid (minute time scale) production of texturized graphitic electrodes for VRFBs through a lowpressure combined gas plasma treatment of GFs in an inductively coupled radio frequency (RF) reactor. By systematically studying the effects of either pure gases, i.e., $\mathrm{O}_{2}$ and $\mathrm{N}_{2}$, or their combination, as well as the gas plasma pressure (set between 4 and $40 \mathrm{~Pa}$ ), the electrodes were optimized to reduce their kinetic polarization toward VRFB reactions. To further enhance the surface area of the electrodes, single-/few-layer graphene, produced by the industrial wet-jet mill (WJM) exfoliation of graphite, were incorporated into GFs through a simple binder-aided infiltration method, dissolving polyvinylidene fluoride (PVDF) as the binder. After gas plasma treatment, the graphene-based electrodes showed a high rate capability. Our optimized VRFBs can efficiently operate in a wide range of $\mathrm{CD}$ current densities, from $25 \mathrm{~mA} \mathrm{~cm}^{-2}(\mathrm{EE}=93.9 \%)$ to 300 $\mathrm{mA} \mathrm{cm}{ }^{-2}(\mathrm{EE}=69.5 \%)$ with optimal cycling stability (over more than 200 cycles). Together with its low additional costs $\left(<100 € \mathrm{~m}^{-2}\right)$ compared to commercial technologies, our electrode technology is market-competitive while showing EE values rivalling the current record-high values.

\section{RESULTS AND DISCUSSION}

\subsection{Combined Multiple Gas Plasma Treatment of GFs.}

In order to increase the electrochemically active surface area of the GFs without affecting the hydraulic permeability, combined multiple gas plasma treatments were investigated to attain a multiscale porosity while creating abundant catalytic sites through the incorporation of heteroatom functionalities. Briefly, the pristine GFs were treated by a combined $\mathrm{O}_{2}$ and $\mathrm{N}_{2}$ plasma using a $\mathrm{O}_{2}: \mathrm{N}_{2}(1: 1 \mathrm{w} / \mathrm{w})$ gas mixture in an inductively coupled $\mathrm{RF}(13.56 \mathrm{MHz})$ reactor. The gas plasma pressure was varied between 4 and $40 \mathrm{~Pa}$ to control the impact energy of the plasma species on the electrode surface, while fixing the plasma power and duration (see Experimental Section). As a comparison, some GFs were treated by either a single gas $\left(\mathrm{O}_{2}\right.$ or $\left.\mathrm{N}_{2}\right)$ plasma step or by two sequential gas plasma steps $\left(\mathrm{O}_{2}\right.$ plasma followed by $\mathrm{N}_{2}$ plasma or $\mathrm{N}_{2}$ plasma followed by $\mathrm{O}_{2}$ plasma). Hereafter, the electrodes treated by one gas plasma are named as X-P, in which $\mathrm{X}$ is the gas used for the plasma treatment (i.e., $\mathrm{O}_{2}, \mathrm{~N}_{2}$, or $\mathrm{O}_{2}: \mathrm{N}_{2}$ ) and $\mathrm{P}$ is the applied gas plasma pressure (i.e., $4 \mathrm{~Pa}, 16 \mathrm{~Pa}$, or $40 \mathrm{~Pa})$. The electrodes treated by sequential plasmas are named $\mathrm{X}+\mathrm{Y}-\mathrm{P}$, where $\mathrm{X}$ and $\mathrm{Y}$ are the gases used during the first and second gas plasmas, respectively. The proposed electrode treatments aim to provide a rapid alternative to the thermal processes commonly performed at high temperature $\left(\geq 400{ }^{\circ} \mathrm{C}\right)$ for several hours (typically $\geq 6$ ). ${ }^{29,64,83}$ Notably, the proposed electrode modification is directly applicable within industrial VRFB supply chains. The rational of our strategy originated from the prior knowledge of standard gas plasma processes. In particular, the $\mathrm{O}_{2}$ plasma creates reactive species, e.g., $\mathrm{O}_{3}$ and $\mathrm{O}$ radicals, ionic species (e.g., $\mathrm{O}^{+}$), and excited states thereof, which can react with carbonaceous surfaces, including the graphitic ones. For example, they can form O-based functionalities (e.g., hydroxyl $(\mathrm{C}-\mathrm{OH})$, carbonyl $(\mathrm{C}=\mathrm{O})$, and carboxyl $(\mathrm{COOH})$ groups and aliphatic hydrocarbons), ${ }^{175,84,176}$ which act as the catalytic sites for the VRFB 
redox reactions. ${ }^{84,92,95,99,100,104-107,147}$ Moreover, morphological modifications of the surface of the carbonaceous materials can also occur during the $\mathrm{O}_{2}$ plasma treatments, as a consequence of the $\mathrm{C}$ losses originated by either $\mathrm{CO}$ or $\mathrm{CO}_{2}$ evolution. ${ }^{84,100}$ Lastly, the $\mathrm{O}_{2}$ plasma treatment is also effective for cleaning the carbonaceous electrode materials from organic contaminations. ${ }^{177}$ Alternatively to the $\mathrm{O}_{2}$ plasma, the $\mathrm{N}_{2}$ plasma creates $\mathrm{N}$ atoms and radicals which effectively form $\mathrm{N}$ based functionalities on carbonaceous surfaces. ${ }^{178,179}$ For example, $\mathrm{N}_{2}$ plasma treatment nitrates graphitic surfaces by generating $\mathrm{C}-\mathrm{N}$ bonds, ${ }^{180}$ thus introducing pyridinic-N, pyrrolic-N, quaternary- $\mathrm{N}, \mathrm{N}$-oxides of pyridinic- $\mathrm{N}$, and aminic-N (more rarely graphitic N). ${ }^{111,176,181,182}$ These functionalities have been demonstrated to be catalytically active for the VRFB redox reactions. ${ }^{101,105,111-113,176}$ In addition, the five valence electrons of $\mathrm{N}$ atoms provide extra charges to the bond of the graphitic layers, enhancing their conductivity. Lastly, $\mathrm{N}_{2}$ plasma can create structural defects, e.g., unsaturated $\mathrm{C}$ atoms, which react with either $\mathrm{O}_{2}$ present in the electrode material or environmental $\mathrm{O}_{2} \cdot{ }^{181}$ Although the aforementioned gas plasma treatments have been consecutively applied to modify GF for their use in VRFBs, ${ }^{176}$ the combination of the $\mathrm{O}_{2}$ and $\mathrm{N}_{2}$ gases during the same plasma process has not been investigated yet. As we will show hereafter, the multiple plasma species in $\mathrm{O}_{2}: \mathrm{N}_{2}$ gas plasma give rise to synergistic effects in modifying the morphological, chemical, physical, and electrochemical properties of the GF surfaces, which can be engineered for the development of efficient VRFBs. The morphological modifications induced by the investigated plasma treatments were evaluated through scanning electron microscopy (SEM) measurements. Figure 1a shows the high magnification SEM image of a single fiber, which exhibits a smooth surface. The SEM image of a bundle of fibers in the pristine GF is shown in Figure $\mathrm{S} 1$. After the $\mathrm{O}_{2}$ plasma at $40 \mathrm{~Pa}\left(\mathrm{O}_{2}-40 \mathrm{~Pa}\right.$ electrode $)$, the

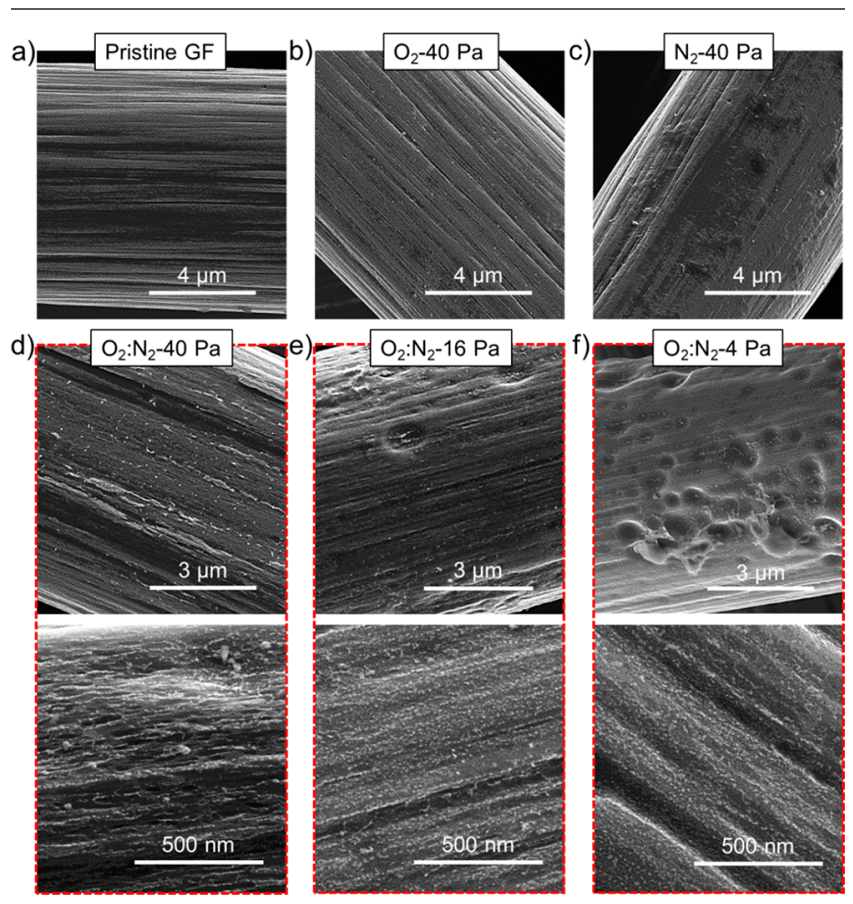

Figure 1. Morphological analysis of the pristine and plasma-treated GFs. SEM images of (a) pristine GF; (b) $\mathrm{O}_{2}-40 \mathrm{~Pa}$; (c) $\mathrm{N}_{2}-40 \mathrm{~Pa}$; (d) $\mathrm{O}_{2}: \mathrm{N}_{2} 40 \mathrm{~Pa}$; (e) $\mathrm{O}_{2}: \mathrm{N}_{2} 16 \mathrm{~Pa}$; and (f) $\mathrm{O}_{2}: \mathrm{N}_{2} 4$ Pa. Panels (d) $-(\mathrm{f})$ include two panels with different magnifications. surface of the fiber still shows a smooth surface (Figure 1b), which is similar to the one observed for the fibers in the pristine GFs. These results agree with previous literature, ${ }^{84,100}$ in which no physical modifications were observed after $\mathrm{O}_{2}$ plasma treatments (however, an excessive applied power, beyond the value here used, might etch the graphitic surfaces via a $\mathrm{CO}$ and/ or $\mathrm{CO}_{2}$ evolution reaction). Contrary to the $\mathrm{O}_{2}$ plasma, the $\mathrm{N}_{2}$ plasma at $40 \mathrm{~Pa}\left(\mathrm{~N}_{2}-40 \mathrm{~Pa}\right.$ electrode $)$ increases the coarseness of the fibers' surface compared to the one of the pristine GF fibers (Figure 1c). This morphology change is caused by the physical etching derived by $\mathrm{N}_{2}$ plasma species impacting onto the GF surface, leading to structural defects (unsaturated $\mathrm{C}$ atoms). ${ }^{181}$ These defects are highly reactive and are expected to react with $\mathrm{O}_{2}$ plasma species, leading to both physical and chemical changes. ${ }^{181}$ Indeed, the $\mathrm{O}_{2}: \mathrm{N}_{2}(1: 1 \mathrm{w} / \mathrm{w})$ plasma at the same pressure $\left(\mathrm{O}_{2}: \mathrm{N}_{2}-40 \mathrm{~Pa}\right.$ electrode $)$ significantly enhances the coarsening of fibers' surfaces (Figure 1d). More in detail, the $\mathrm{O}_{2}$ plasma species oxidize the fibers' surfaces, while the $\mathrm{N}_{2}$ plasma species progressively etch the surface. The etching caused by the $\mathrm{N}_{2}$ plasma species is promoted by the concomitant oxidation of the surface, while the oxidation is accelerated by the formation of structural defects. ${ }^{181}$ Thus, the synergistic effects of the plasma species of two different gases foster "deeper" etching effects compared to the case of single gas plasmas. Beyond the gas plasma composition, the pressure of the plasma can significantly affect the morphology and chemistry of the final GF surface. More in detail, the mean free path between plasma species decreases with decreasing the plasma pressure. Consequently, the lower is the pressure, the longer is the mean acceleration time of the plasma species, which then impacts the surface of the treated sample with higher energy, boosting both the chemical modifications and the physical etching. Indeed, the $\mathrm{O}_{2}: \mathrm{N}_{2}(1: 1$ $\mathrm{w} / \mathrm{w})$ plasma at $16 \mathrm{~Pa}\left(\mathrm{O}_{2}: \mathrm{N}_{2}-16 \mathrm{~Pa}\right.$ electrode $)$ and the $\mathrm{O}_{2}: \mathrm{N}_{2}$ (1:1) plasma at $4 \mathrm{~Pa}\left(\mathrm{O}_{2}: \mathrm{N}_{2}-4 \mathrm{~Pa}\right.$ electrode $)$ lead to a multiscale texturization of the fibers' surfaces (Figure 1e,f), which shows (1) crater-like cavities with diameters ranging from a few hundreds of nanometers to above $1 \mu \mathrm{m}$ (microtexturization) and (2) abundant and uniformly distributed micropores resulting in a nanoparticle-like appearance (nanotexturization).

The microtexturization is significantly more pronounced in $\mathrm{O}_{2}: \mathrm{N}_{2}-4 \mathrm{~Pa}$ compared to $\mathrm{O}_{2}: \mathrm{N}_{2}-16 \mathrm{~Pa}$, as expected by the above discussion of the gas plasma processes. As shown by the subsequent electrochemical characterization, the multiscale texturization of the electrodes ensures an optimal hydraulic permeability by maintaining the macroscopic pathways for the electrolyte flow exhibited in the pristine GFs, while providing an elevated catalytic surface area for carrying out the redox reactions.

As above-discussed, the surface chemistry plays a crucial role in determining the catalytic activity of the VRFB electrodes. ${ }^{183,184}$ Therefore, X-ray photoelectron spectroscopy (XPS) measurements were performed to evaluate the functional groups formed on the GF surface during the gas plasma treatments. The XPS wide scans of the various electrodes are reported in Figure $\mathrm{S} 2$, while the high-resolution spectra of the regions of $\mathrm{C} 1 \mathrm{~s}, \mathrm{O} 1 \mathrm{~s}$, and $\mathrm{N} 1 \mathrm{~s}$ are shown in Figures S3-S5, respectively. As shown in Figure $2 \mathrm{a}$, all the plasma treatments significantly increase both $\mathrm{O}$ and $\mathrm{N}$ functionalities. The $\mathrm{O}_{2}: \mathrm{N}_{2}-4 \mathrm{~Pa}$ electrode shows the maximum $\mathrm{O}$ relative atomic percentage (at. \%) of $15.9 \%$, followed by $\mathrm{O}_{2}: \mathrm{N}_{2}-40 \mathrm{~Pa}$ and $\mathrm{O}_{2}: \mathrm{N}_{2}-16 \mathrm{~Pa}$ (15.2\% and $14.2 \%$, respectively). Importantly, such $\mathrm{O}$ at. $\%$ values are significantly higher than those reported in the literature for thermally treated GFs optimized for VRFBs (typically lower than 8\%). ${ }^{29,76}$ 

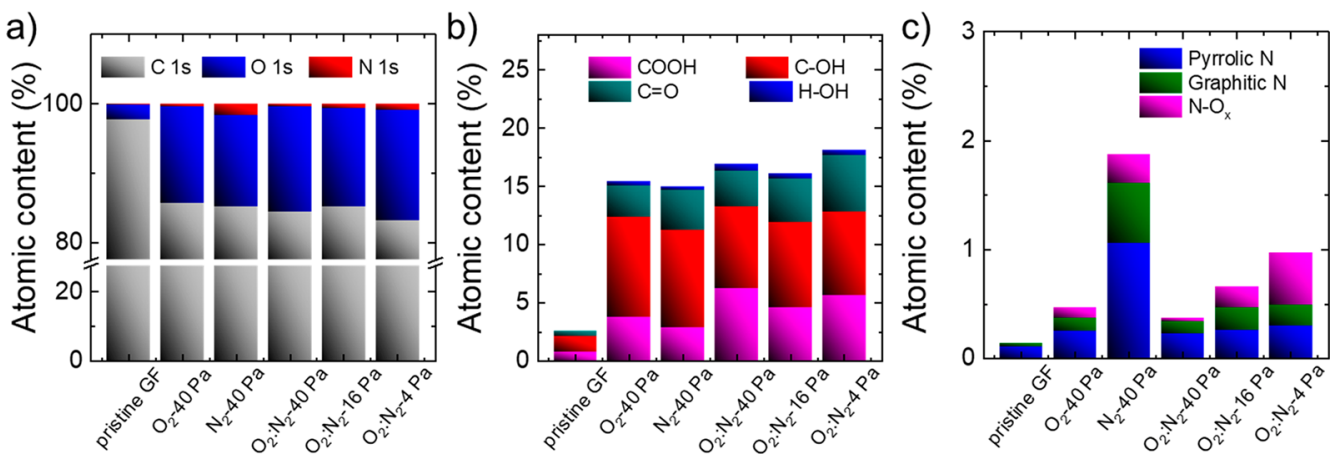

Figure 2. Chemical characterization of the pristine and plasma-treated GFs. (a) Elemental composition of the electrodes. (b) O and (c) N functionality distributions of the electrodes. The data have been estimated from the analysis of the XPS spectra (wide scan, C 1s, O $1 \mathrm{~s}$, and N 1s spectra).
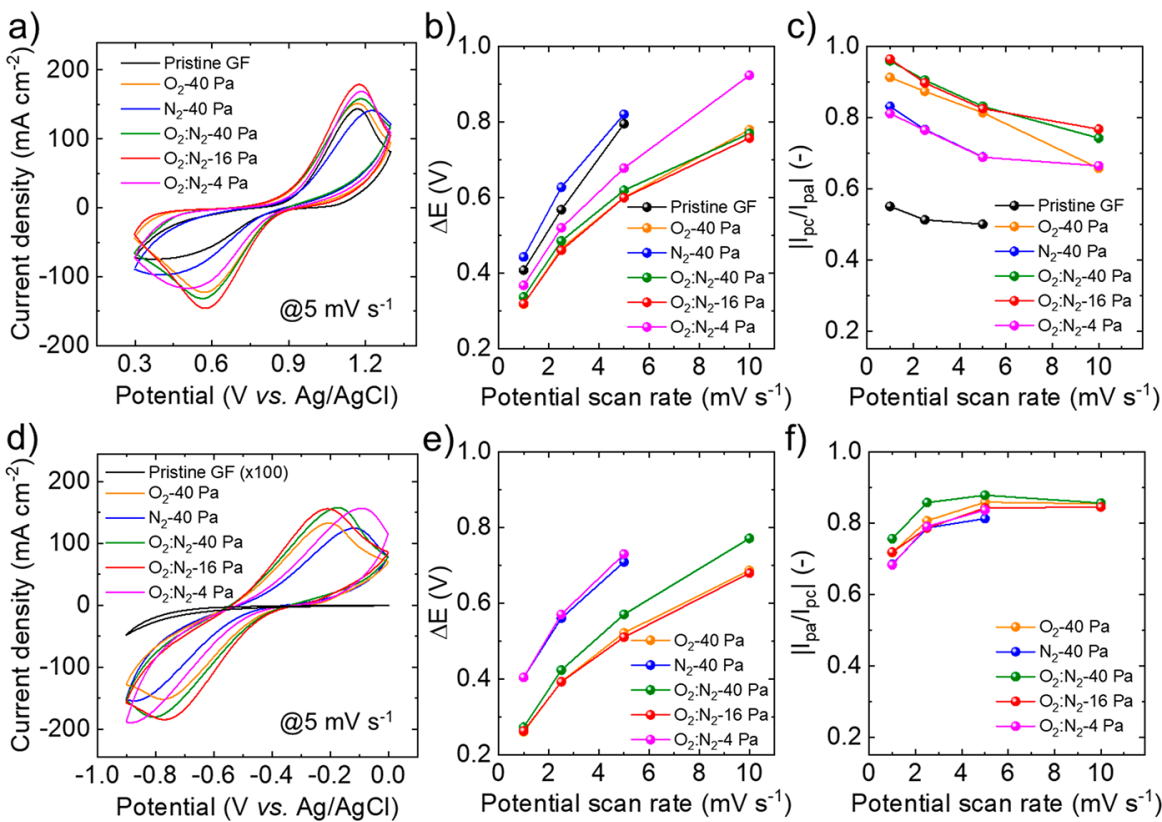

Figure 3. Electrochemical characterization of the pristine and plasma-treated GFs. (a) CV curves measured for the investigated electrodes in the $0.1 \mathrm{M}$ $\mathrm{VOSO}_{4}+3 \mathrm{M} \mathrm{H}_{2} \mathrm{SO}_{4}$ solution for the $\mathrm{VO}^{2+} / \mathrm{VO}_{2}^{+}$(positive) VRFB reaction at a scanning potential rate of $10 \mathrm{mV} \mathrm{s}{ }^{-1}$. (b) Analysis of $\Delta E$ and (c) $I_{\mathrm{pc}}$ / $I_{\mathrm{pa}}$ (extrapolated by the CV curves shown in panel a). (d) CV curves measured for the investigated electrodes in the $0.1 \mathrm{M} \mathrm{VOSO}_{4}+3 \mathrm{M} \mathrm{H}_{2} \mathrm{SO}_{4}$ solution for the $\mathrm{V}^{2+} / \mathrm{V}^{3+}$ (negative) VRFB reaction at a scanning potential rate of $10 \mathrm{mV} \mathrm{s}^{-1}$. (e) Analysis of $\Delta E$ and (f) $I_{\mathrm{pc}} / I_{\mathrm{pa}}$ (extrapolated by the CV curves shown in panel d). The current densities in (a) and (d) were calculated by normalizing the measured currents to the planar area of one face of the electrodes.

Thanks to the surface selectivity of the plasma treatments, a high surface oxidation of the GF can be obtained without altering the bulk properties, resulting in the optimal electrochemical performance (as we will show below). The maximum at. \% of $\mathrm{N}$ is found for $\mathrm{N}_{2}-40 \mathrm{~Pa}(1.7 \%)$, followed by $\mathrm{O}_{2}: \mathrm{N}_{2}-16 \mathrm{~Pa}$ and $\mathrm{O}_{2}: \mathrm{N}_{2}-4 \mathrm{~Pa}(0.7 \%$ and $0.9 \%$, respectively). As shown in the $\mathrm{C} 1 \mathrm{~s}$ spectra, all the plasma treatments decrease the at. \% of the $\mathrm{C}=\mathrm{C}$ states and their satellite feature $\left(\pi-\pi^{*}\right.$ peak), which means that the graphitic states ( $\mathrm{sp}^{2}$ hybridization) are converted to other states, including $\mathrm{sp}^{3}$ hybridized states (which are mainly ascribed to the amorphous carbon ${ }^{185}$ or carbon adatoms ${ }^{185,186}$ ), vacancylike defects (which likely refer to plasma etching-induced structural modifications, e.g., pentagon, heptagon, and octagon carbon rings ${ }^{185-187}$ ), and heteroatomic functional groups.

The distributions of the $\mathrm{O}$ and $\mathrm{N}$ functionalities for the investigated electrodes were evaluated by the analyses of the $\mathrm{O}$ 1s (Figure S4) and N 1s spectra (Figure S5), respectively. As shown in Figure $2 b$, the plasma treatments increase the at. \% of the carbonyl groups $(\mathrm{C}=\mathrm{O})$, hydroxyl groups $(\mathrm{C}-\mathrm{OH})$, and carboxyl groups $(\mathrm{COOH})$, the latter two not shown by pristine GFs. All these $O$ functionalities have been proposed to be catalytic sites for the VRFB redox reactions. ${ }^{76,84,92,95,99,100,104-107,147,188,189}$ Furthermore, the plasma treatments introduce $\mathrm{N}$ groups, namely pyrrolic $\mathrm{N}$, graphitic $\mathrm{N}$, and $\mathrm{N}$ oxides $\left(\mathrm{N}-\mathrm{O}_{x}\right)$, as illustrated in Figure 2c. Differently from $\mathrm{N}$-doped electrodes obtained through high-temperatureassisted chemical functionalization, ${ }^{190}$ no pyridinic groups were observed in our case. As previously demonstrated, N functionalities can act as catalytic sites for the VRFB redox reactions beyond the $\mathrm{O}$ functionalities, ${ }^{101,105,111-113}$ with which they may lead to synergistic catalytic effects. ${ }^{105,176,191}$

Since the VRFBs operate in aqueous media, their electrodes must exhibit an optimal water wetting to guarantee an elevated electrolyte accessibility to the catalytic sites, as well as to increase the hydraulic permeability. Water contact angle measurements show that the surface of the pristine GF is hydrophobic (water contact angle $\left.=122.9^{\circ} \pm 4.9^{\circ}\right)$. Differently, the plasma-treated electrodes exhibit a zero-water contact angle (see Movie S1). 
The conversion of the GF surface from hydrophobic to hydrophilic is directly attributed to the introduction of the polar groups of either $\mathrm{O}$ or $\mathrm{N}$ functionalities. ${ }^{192,193}$

2.2. Electrode Characterization. Cyclic voltammetry (CV) measurements in a three-electrode cell configuration were carried out to evaluate the catalytic activity of the pristine GF and the plasma-treated GFs toward the VRFB redox reactions. The catalytic properties of the electrodes can be evaluated from the analysis of the separation of the potentials of the current density peaks for the redox reactions $(\Delta E),{ }^{194-196}$ as well as from the corresponding ratio of the anodic/cathodic or cathodic/anodic current density peaks $\left(I_{\mathrm{pa}} / I_{\mathrm{pc}}\right.$ or $\left.I_{\mathrm{pc}} / I_{\mathrm{pa}}\right){ }^{194-196}$ The measurements were performed at potential scan rates ranging from 1 to $10 \mathrm{mV} \mathrm{s}^{-1}$ in $0.1 \mathrm{M} \mathrm{VOSO}_{4}+3 \mathrm{M} \mathrm{H}_{2} \mathrm{SO}_{4}$ solution. Even though this electrolyte is substantially different from the those typically used for the full VRFB systems (typically $\geq 1 \mathrm{M} \mathrm{VO}^{2+}+3 \mathrm{M} \mathrm{H}_{2} \mathrm{SO}_{4}$ and $\geq 1 \mathrm{M} \mathrm{V}^{3+}+3 \mathrm{M} \mathrm{H}_{2} \mathrm{SO}_{4}$ for the starting catholyte and anolyte, respectively), such analysis can qualitatively compare the behavior of the electron transfer kinetics for the VRFB reactions among different electrodes. Figure 3a shows the CV curves measured for the investigated electrodes between 0.3 and $1.3 \mathrm{~V}$ vs $\mathrm{Ag} / \mathrm{AgCl}$, in which the $\mathrm{VO}^{2+} / \mathrm{VO}_{2}{ }^{+}$redox reaction occurs, ${ }^{197,198}$ at a potential scan rate of $5 \mathrm{mV} \mathrm{s}^{-1}$. The $\mathrm{O}_{2}: \mathrm{N}_{2}-16 \mathrm{~Pa}$ electrode shows the highest anodic current density among the investigated electrodes, followed by the $\mathrm{O}_{2}: \mathrm{N}_{2}-4 \mathrm{~Pa}$ electrode. This trend can be associated with the superior surface area of the $\mathrm{O}_{2}: \mathrm{N}_{2}-16 \mathrm{~Pa}$ and $\mathrm{O}_{2}: \mathrm{N}_{2}-4 \mathrm{~Pa}$ electrodes, as shown by SEM analysis (Figure 1 ). Figure $3 \mathrm{~b}, \mathrm{c}$ shows $\Delta E$ and $\mid I_{\mathrm{pc}} / I_{\mathrm{pa}} \mathrm{l}$, respectively, measured for the investigated electrodes as a function of the potential scan rate. At $10 \mathrm{mV} \mathrm{s}^{-1}$, no cathodic peaks were observed for the pristine GF and the $\mathrm{N}_{2}-40 \mathrm{~Pa}$ electrode within the selected potential range. The $\mathrm{O}_{2}: \mathrm{N}_{2}-16 \mathrm{~Pa}$ electrode shows the lowest $\Delta E$ values $(\sim 0.32$ and $\sim 0.76 \mathrm{~V}$ at 1 and $10 \mathrm{mV} \mathrm{s}^{-1}$, respectively), indicating low overpotential for the $\mathrm{VO}^{2+} / \mathrm{VO}_{2}{ }^{+}$redox reaction. The pristine GF shows the lowest $I I_{\mathrm{pc}} / I_{\mathrm{pa}} \mid$ values $(<0.6)$, which means a poor reversibility of the $\mathrm{VO}^{2+} / \mathrm{VO}_{2}{ }^{+}$redox reaction. ${ }^{194-196}$ The highest $\left|I_{\mathrm{pc}} / I_{\mathrm{pa}}\right|$ values are measured for the $\mathrm{O}_{2}: \mathrm{N}_{2}-16 \mathrm{~Pa}$ electrode, followed by the $\mathrm{O}_{2}: \mathrm{N}_{2}-40 \mathrm{~Pa}$ electrode. For these cases, the $\left|I_{\mathrm{pc}} / I_{\mathrm{pa}}\right|$ values are higher than 0.9 for the potential scan rate equal or inferior to $2.5 \mathrm{mV} \mathrm{s}^{-1}$. Although the $\mathrm{O}_{2}-40 \mathrm{~Pa}$ electrode shows $\Delta E$ and $I_{\mathrm{pc}} / I_{\mathrm{pa}}$ similar to those of the $\mathrm{O}_{2}: \mathrm{N}_{2}-16$ $\mathrm{Pa}$ electrode at a low potential scan rate (i.e., $\leq 5 \mathrm{mV} \mathrm{s}^{-1}$ ), its performances (in particular $\left|I_{\mathrm{pc}} / I_{\mathrm{pa}}\right|$ ) are inferior to those of the most performing electrodes with increasing the potential scan rate to $10 \mathrm{mV} \mathrm{s}^{-1}$. These effects can negatively affect high-power operation of the VRFBs based on $\mathrm{O}_{2}-40 \mathrm{~Pa}$ electrodes (see the result in Section 2.3). Figure 3d shows the CV curves of the investigated electrodes between -0.9 and $-0.0 \mathrm{~V} \mathrm{vs} \mathrm{Ag} / \mathrm{AgCl}$, in which the $\mathrm{V}^{2+} / \mathrm{V}^{3+}$ redox reaction occurs, ${ }^{197}$ at a potential scan rate of $5 \mathrm{mV} \mathrm{s}^{-1}$.

The $\mathrm{O}_{2}: \mathrm{N}_{2}-40 \mathrm{~Pa}, \mathrm{O}_{2}: \mathrm{N}_{2}-16 \mathrm{~Pa}$, and $\mathrm{O}_{2}: \mathrm{N}_{2}-4 \mathrm{~Pa}$ exhibit the highest current densities, likely due to their large surface areas. No clear anodic and cathodic peaks were observed for pristine GFs, indicating marginal catalytic activity for the $\mathrm{V}^{2+} / \mathrm{V}^{3+}$ redox reaction. As shown in Figure $3 \mathrm{e}$, the $\mathrm{O}_{2}: \mathrm{N}_{2}-16 \mathrm{~Pa}$ electrode shows the lowest $\Delta E$ values $\left(0.26\right.$ and $0.68 \mathrm{~V}$ at 1 and $10 \mathrm{mV} \mathrm{s}^{-1}$, respectively). Figure $3 \mathrm{f}$ shows that the $\left|I_{\mathrm{pa}} / I_{\mathrm{pc}}\right|$ values at the potential rate of $10 \mathrm{mV} \mathrm{s}^{-1}$ are similar for the $\mathrm{O}_{2}: \mathrm{N}_{2}-16 \mathrm{~Pa}$ and $\mathrm{O}_{2}-40 \mathrm{~Pa}$ electrodes, indicating comparable reversibility of the $\mathrm{V}^{2+} / \mathrm{V}^{3+}$ redox reaction. By decreasing the potential scan rate, the $\left|I_{\mathrm{pa}} / I_{\mathrm{pc}}\right|$ values decrease, likely due to the occurrence of the hydrogen evolution reaction (which is however eliminated in
VRFBs working in proper voltage windows that guarantee high Coulombic efficiency, CE) ${ }^{199}$ Importantly, the electrodes displaying a lower content of $\mathrm{N}$ functionalities (i.e., $\mathrm{O}_{2}-40 \mathrm{~Pa}$ and $\mathrm{O}_{2}: \mathrm{N}_{2}-40 \mathrm{~Pa}$, see Figure 2c) exhibit the highest redox reaction reversibility (i.e., $\left|I_{\mathrm{pa}} / I_{\mathrm{pc}}\right|$ values). This trend suggests that the $\mathrm{N}$ functionalities are the catalytic sites for the hydrogen evolution reaction, in agreement with previous literature. ${ }^{200,201}$ Noteworthy, the hydrogen evolution reaction may be hindered in VRFBs operating at higher electrolyte concentration lowering the overpotential for the $\mathrm{V}^{2+} / \mathrm{V}^{3+}$ redox reaction. ${ }^{199}$ Figure S6 shows $I_{\mathrm{pa}}$ and $I_{\mathrm{pc}}$ respectively, measured for the investigated electrodes as a function of the square root of the potential scan rate, for both the $\mathrm{VO}^{2+} / \mathrm{VO}_{2}{ }^{+}$and the $\mathrm{V}^{2+} / \mathrm{V}^{3+}$ redox reactions. The linear behavior of the curves indicates that the redox reactions are limited by the transport of the reactants toward the electrode surface, in agreement with the Randles-Sevick equation. ${ }^{194-196,202}$ Moreover, the slopes of the $I_{\mathrm{pc}}$ and $I_{\mathrm{pa}} \mathrm{vs}$ (potential scan rate) ${ }^{1 / 2}$ plots of the gas plasma treated electrode are higher than the one of the GF (measured only for $\mathrm{VO}^{2+}$ / $\mathrm{VO}_{2}{ }^{+}$redox reactions). This means that the chemical and morphology modification of the GF through the gas plasma treatment positively affect the reactant transfer rate toward the catalytic sites of the electrodes. ${ }^{145,203}$

2.3. Evaluation of the Plasma-Treated ElectrodeBased VRFB Performance. The plasma-treated GFs were evaluated in VRFBs using a no-gap serpentine architecture, ${ }^{204,205}$ Nafion 115 (thickness of $127 \mu \mathrm{m}$ ) as the proton exchange membrane, and $1 \mathrm{MVO}^{2+}+3 \mathrm{M} \mathrm{H}_{2} \mathrm{SO}_{4}$ and $1 \mathrm{MV}^{3+}+$ $3 \mathrm{M} \mathrm{H}_{2} \mathrm{SO}_{4}$ as the starting catholyte (positive electrolyte) and anolyte (negative electrolyte), respectively. Hereafter, the VRFBs are named with the nomenclature used for their electrodes. First, polarization curve analysis was performed to evaluate the kinetic activation polarizations (kinetic losses) and the ohmic polarizations (iR losses) of the cells. ${ }^{79,80}$ Figure $4 \mathrm{a}$
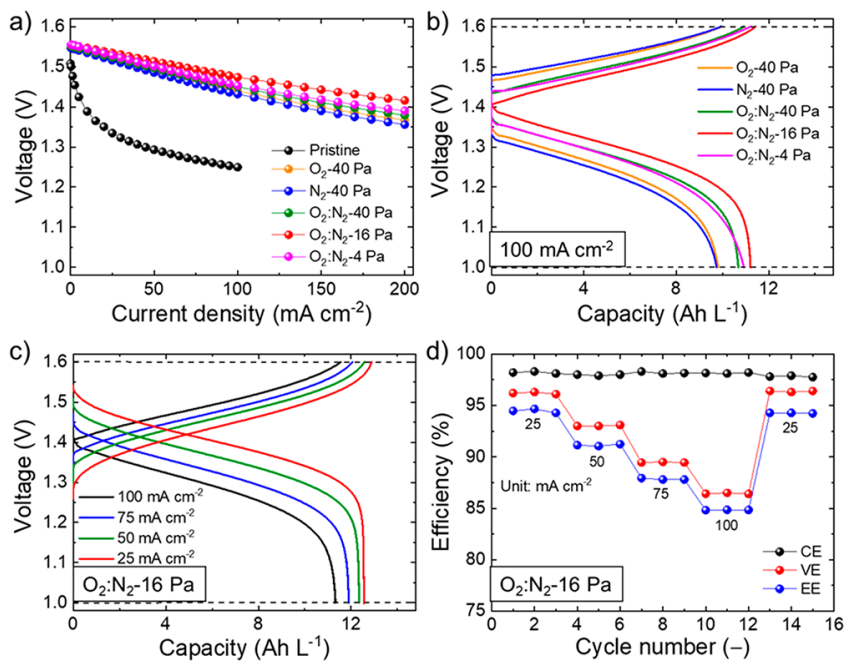

Figure 4. Electrochemical characterization of the VRFBs based on plasma-treated GFs using Nafion 115 as the proton-exchange membrane. (a) $i R$-corrected polarization curves measured for the VRFBs using pristine GFs or plasma-treated electrodes. (b) CD curves measured for the investigated VRFBs at a current density of $100 \mathrm{~mA}$ $\mathrm{cm}^{-2}$. (c) CD curves measured for the $\mathrm{O}_{2}: \mathrm{N}_{2}-16 \mathrm{~Pa}$ VRFB at various current densities $\left(25,50,75\right.$, and $\left.100 \mathrm{~mA} \mathrm{~cm}^{-2}\right)$. (d) Efficiency metrics (CE, VE, and EE) of the $\mathrm{O}_{2}: \mathrm{N}_{2}-16 \mathrm{~Pa}$ VRFB using Nafion 115 extrapolated from the $\mathrm{CD}$ curve analysis as a function of the cycle number at various current densities. 
shows the $i R$-corrected polarization curves measured for the investigated VRFBs, specifically evidencing the kinetic losses resulting from the catalytic activity of the electrodes toward the VRFB redox reactions. ${ }^{79,80}$ The raw polarization curves, which include the $i R$ losses attributed to the resistance of the proton exchange membrane, the bipolar plates, and the current collectors, are reported in Figure S7. Clearly, the VRFBs based on plasma-treated electrodes significantly decrease the kinetic losses of the cell based on pristine GFs, in agreement with the $\mathrm{CV}$ data. The $\mathrm{O}_{2}: \mathrm{N}_{2}-40 \mathrm{~Pa}$ VRFB shows the lowest kinetic losses, e.g., $\sim 0.048, \sim 0.095$, and $\sim 0.167 \mathrm{~V}$ at 50,100 , and 200 $\mathrm{mA} \mathrm{cm}{ }^{-2}$, respectively. In addition, we point out that the use of electrodes treated with two different gas plasmas (i.e., $\mathrm{O}_{2}+\mathrm{N}_{2}-16$ $\mathrm{Pa}$ and $\mathrm{N}_{2}+\mathrm{O}_{2}-16 \mathrm{~Pa}$ ) results in VRFBs with kinetic losses higher than those of the VRFBs using electrodes treated by lowpressure combined gas plasma (see Figure S8). Galvanostatic charge/discharge (CD) analysis was carried out to evaluate the efficiency metrics (i.e., the $\mathrm{CE}$, the VE, and the $\mathrm{EE}$ ) of the investigated VRFBs. Figure $4 \mathrm{~b}$ shows the CD curves (second cycle) for the investigated VRFBs at the current density of 100 $\mathrm{mA} \mathrm{cm}{ }^{-2}$. The upper voltage limit was fixed to $1.6 \mathrm{~V}$ in order to avoid parasitic reactions (i.e., water splitting reactions), in agreement with the best practices provided in literature. ${ }^{197}$ In agreement with our CV analysis, the $\mathrm{O}_{2}: \mathrm{N}_{2}-16$ Pa VRFB shows the best electrochemical performance, reaching a discharge specific capacity of $11.2 \mathrm{Ah} \mathrm{L}^{-1}$. These values correspond to an electrolyte utilization (EU) of $83.6 \%$, being the theoretical capacity calculated on the total volume of the electrolyte, including both catholyte and anolyte, equal to $13.4 \mathrm{Ah} \mathrm{L}^{-1}$. Figure $4 c$ reports the $C D$ curves measured for $\mathrm{O}_{2}: \mathrm{N}_{2}-16 \mathrm{~Pa}$ VRFB at different current densities, ranging from 25 to $100 \mathrm{~mA}$ $\mathrm{cm}^{-2}$. As expected, the capacity increases with decreasing the current density because of the reduced polarization losses. At 25 $\mathrm{mA} \mathrm{cm}{ }^{-2}$, the capacity reaches values as high as $\sim 12.5 \mathrm{Ah} \mathrm{L}^{-1}$, corresponding to an EU of $93.6 \%$. Figure $4 \mathrm{~d}$ shows the rate capability of the $\mathrm{O}_{2}: \mathrm{N}_{2}-16 \mathrm{~Pa}$ VRFB, showing the efficiency metrics over consecutive $\mathrm{CD}$ cycles at different current densities. At $100 \mathrm{~mA} \mathrm{~cm}^{-2}$, the VRFB reaches a VE and an EE as high as $86.5 \%$ and $84.9 \%$, which are among the highest values reported for VRFB using Nafion membranes with a thickness similar to our case (i.e., Nafion 115 or Nafion 117). ${ }^{127,147,206}$ Similar or higher values have been recently reported using thinner Nafion membranes, e.g., Nafion 212 (thickness $=50.8 \mu \mathrm{m}$ ), Nafion 211 (thickness $=25.4 \mu \mathrm{m}$ ), or Nafion XL (thickness $=27.5$ $\mu \mathrm{m}) .{ }^{29,76,125}$ However, the latter systems are commonly tested at a current density superior to 100 or even $200 \mathrm{~mA} \mathrm{~cm}^{-2}$, since they poorly perform during low-power density conditions due to the low CE $(<95 \%)$ resulting by the cross-mixing of the vanadium species through thin Nafion membranes. Despite these issues, we anticipate that optimized VRFBs using a thin Nafion membrane (i.e., Nafion XL, thickness $=27.5 \mu \mathrm{m}$ ) will be shown later in the text for high power density applications. The main efficiency metrics of the VRFBs extrapolated by the galvanostatic $\mathrm{CD}$ measurements at various current densities are summarized in Table S1.

\section{APPLICABILITY OF THE GAS PLASMA TREATMENTS ON HIERARCHICAL GRAPHENE-COATED ELECTRODES}

The applicability of the rapid combined plasma treatments was preliminarily evaluated for advanced hierarchical electrodes produced by decorating GF fibers with graphene flakes, aiming to increase the catalytic surface area of the GFs. Herein, hierarchical graphitic electrodes were produced by coating the GF with graphene. In order to maintain an industrial approach for the electrode fabrication, single-/few-layer graphene (SLG/ FLG) flakes were produced through scalable wet-jet milling (WJM) exfoliation of graphite in $N$-methyl-2-pyrrolidone dispersion (see details in the Supporting Information). ${ }^{207-209}$ Briefly, the WJM exfoliation process makes use of a high pressure $(180-250 \mathrm{MPa})$ to transform a graphite dispersion in two jet streams, which then recombine in a small nozzle (diameter between 0.3 and $0.1 \mathrm{~nm}$ ), where the generated shear forces cause the exfoliation of the graphite in single-/few-layer graphene flakes. ${ }^{207,208,210}$ By applying three consecutive WJM passes on nozzles with diameters of $0.3,0.15$, and $0.1 \mathrm{~nm}$, respectively, our WJM protocols lead to a highly concentrated dispersion $(\sim 10 \mathrm{~g}$ $\mathrm{L}^{-1}$ ) of graphene flakes with an exfoliation yield of $\sim 100 \%$ and a graphene production rate of $\sim 2 \mathrm{~g} \mathrm{~min}^{-1} .{ }^{207,208,211}$ These values satisfy the requirements for high-throughput manufacturing chains of graphene-based commercial products. ${ }^{212,213}$ The thorough characterization of the WJM-produced graphene flakes is reported in the Supporting Information (Figures S9 and S10). Importantly, as shown in previous works, ${ }^{209}$ WJMproduced SLG/FLG flakes are pristine graphene flakes that do not exhibit basal plane defects, as also evidenced by Raman analysis (see Figure S10b). Consequently, they can guarantee superior electrical properties compared to other commercialized graphene derivatives, including graphene oxide and reduced graphene oxide. The hierarchical electrodes were produced by infiltrating the WJM-produced graphene dispersion mixed with polyvinylidene fluoride (PVDF) binder (weight percentage, wt $\%=10 \%$ ) into GFs (graphene mass loading of $20 \mathrm{mg} \mathrm{cm}^{-2}$ ). The so-produced electrodes are herein named GF/graphene. Noteworthy, the graphene production rate of the WJM process is compatible with a production of $28 \mathrm{~m}^{2}$ of electrodes per day. The additional material cost of our graphene-based electrodes is currently inferior to $100 € \mathrm{~m}^{-2}$. Electrodes without the PVDF binder were also tested as a comparison to elucidate the adhesion effects between graphene and GF for the achievement of a durable electrodes performance. However, graphene flakes easily detached from the GF surface, leading to both poor data reproducibility and fast degradation of the VRFB performances during the electrochemical tests. As shown by the cross-section SEM images of a graphene/GF (Figures 5a,b), the GF fibers are
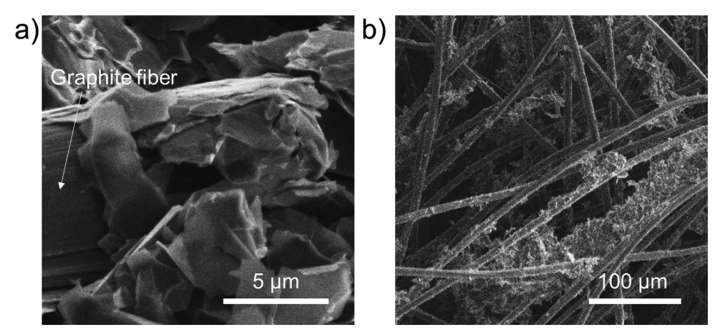

Figure 5. Morphological analysis of the GF/graphene electrodes. (a, b) Cross-sectional SEM images of the graphene- $\mathrm{O}_{2}: \mathrm{N}_{2}-4 \mathrm{~Pa}$ electrode.

wrapped by the graphene flakes, which also form clusters within the fiber-based felt network. The Brunauer-Emmett-Teller (BET) surface area of both the GF and the GF/graphene electrode was estimated by analyzing $\mathrm{Kr}$ physisorption measurements performed at $77 \mathrm{~K} .^{214,215}$ The BET specific surface area of native GFs was $\sim 0.4 \mathrm{~m}^{2} \mathrm{~g}^{-1}$, while it increased up to $\sim 3.4 \mathrm{~m}^{2} \mathrm{~g}^{-1}$ $(+750 \%)$ for GF/graphene. 
The low-pressure combined gas plasma treatments proposed for the pristine GFs were then applied to the so-produced GF/ graphene, obtaining the electrodes herein named graphene$\mathrm{O}_{2}: \mathrm{N}_{2}-\mathrm{X} \mathrm{Pa}$, in which $\mathrm{X}$ indicates the pressure of the gas plasma processes (i.e., 40,16 , or $4 \mathrm{~Pa}$ ). Preliminary studies through polarization curve measurements on symmetric VRFBs also evaluated the electrochemical performance of $\mathrm{GF} /$ graphene electrodes treated with single gas plasma (i.e., $\mathrm{O}_{2}-40 \mathrm{~Pa}$ and $\mathrm{N}_{2}-$ $40 \mathrm{~Pa})$. Overall, our preliminary results indicated that the most performant VRFBs were those based on graphene- $\mathrm{O}_{2}: \mathrm{N}_{2}-16 \mathrm{~Pa}$ and graphene- $\mathrm{O}_{2}: \mathrm{N}_{2}-4 \mathrm{~Pa}$, to which the discussion is directed hereafter. Noteworthy, the investigated gas plasma processes can also induce morphological and chemical modifications on the graphitic structure of WJM-produced graphene flakes, beyond the changes in the underlying GFs discussed in the previous section. However, the evaluation of the effects of the gas plasma parameters on the properties of the graphene flakes, as well as the optimization of the electrochemical performance of the corresponding graphene, is beyond the scope of this work and can be a subject matter of future studies. Figure S11 shows the polarization curves measured for the VRFBs using Nafion 115 as the proton-exchange membrane and based on low-pressure combined gas plasma-treated GF/graphene electrodes, namely, graphene- $\mathrm{O}_{2}: \mathrm{N}_{2}-16 \mathrm{~Pa}$ and graphene- $\mathrm{O}_{2}: \mathrm{N}_{2}-4 \mathrm{~Pa}$, in comparison to the curve measured for the reference without graphene (i.e., $\mathrm{O}_{2}: \mathrm{N}_{2}-16 \mathrm{~Pa}$ ). Noteworthy, the incorporation of graphene flakes into the GF reduces the kinetic losses of the reference cell as a consequence of the increase of the number of electrode catalytic sites, likely introduced in the form of either $\mathrm{O}$ or $\mathrm{N}$ functionalities introduced by the plasma treatments. ${ }^{216,217}$ The lowest polarization losses were measured for graphene- $\mathrm{O}_{2}: \mathrm{N}_{2}-4$ $\mathrm{Pa}$. Figure S12 shows the comparison between the $\mathrm{CD}$ curves (second cycle) measured for the optimized VRFBs with and without graphene (i.e., $\mathrm{O}_{2}: \mathrm{N}_{2}-16 \mathrm{~Pa}$ and graphene- $\mathrm{O}_{2}: \mathrm{N}_{2}-4 \mathrm{~Pa}$ ) at the current density of $100 \mathrm{~mA} \mathrm{~cm}{ }^{-2}$. The graphene- $\mathrm{O}_{2}: \mathrm{N}_{2}-4$ Pa VRFB exhibits the highest discharge capacity of $11.9 \mathrm{Ah} \mathrm{L}^{-1}$, which corresponds to an EU of $88.8 \%(+6.2 \%$ compared to the graphene-free reference). Figure $6 \mathrm{a}$ reports the $\mathrm{CD}$ curves measured for the graphene- $\mathrm{O}_{2}: \mathrm{N}_{2}-4 \mathrm{~Pa}$ VRFB using Nafion 115 as the proton-exchange membrane at various current densities, ranging from 25 to $100 \mathrm{~mA} \mathrm{~cm}{ }^{-2}$. At the lowest current density of $25 \mathrm{~mA} \mathrm{~cm}^{-2}$, the cell reached an EE as high as $\sim 93.9 \%$. At 100 $\mathrm{mA} \mathrm{cm}{ }^{-2}$, the cells still show a high EE of $85.1 \%$, which is the result of a high VE (86.9\%). To fully exploit the low kinetic activation polarization of our graphene-based VRFBs, a thin Nafion XL was used as the proton-exchange membrane to reduce the ohmic polarization losses of the Nafion 115. Nafion $\mathrm{XL}$ consists of a microporous polytetrafluoroethylene (PTFE)rich support layer $(\sim 10 \mu \mathrm{m})$ impregnated on both sides with dense Nafion layer $(\sim 10 \mu \mathrm{m}){ }^{218}$ Thanks to this three-layer structure, Nafion XL membranes demonstrated superior performance compared to their unreinforced analogue, ${ }^{219}$ since it combined the advantages of microporous PTFE as a mechanical reinforcement, ${ }^{218,219}$ and thin $(\sim 27.5 \mu \mathrm{m})$ Nafion membrane as a fast-ion transporting channel. ${ }^{218-220}$ Figure S13 compares the polarization curves measured for graphene- $\mathrm{O}_{2}: \mathrm{N}_{2}$ $4 \mathrm{~Pa}$ VRFBs using Nafion 115 or Nafion XL, evidencing that the impact of the ohmic polarization losses is significantly weakened for the case of Nafion XL. Figure $6 \mathrm{~b}$ shows that the graphene$\mathrm{O}_{2}: \mathrm{N}_{2}-4$ Pa VRFB using Nafion XL can efficiently operate at a current density as high as $300 \mathrm{~mA} \mathrm{~cm}^{-2}$, at which it shows a VE and an EE of $70.3 \%$ and $69.5 \%$, respectively. Figure $6 c$,d reports
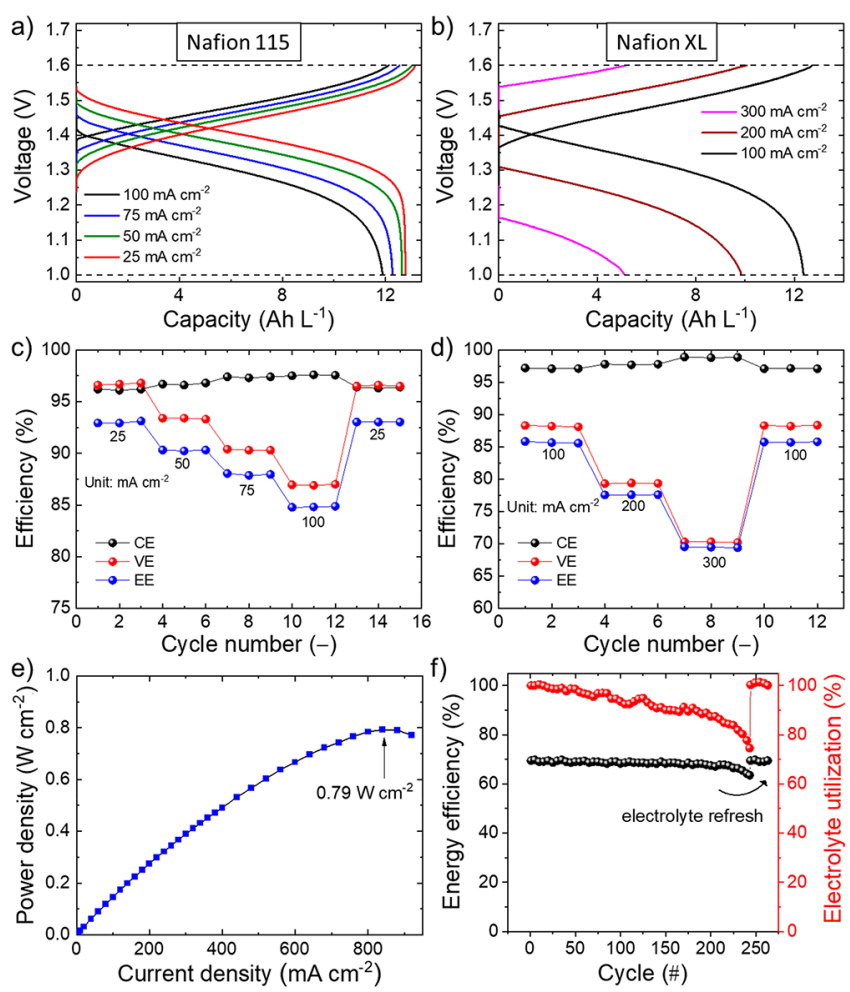

Figure 6. Electrochemical characterization of the VRFBs based on plasma-treated GF/graphene electrodes. (a) $\mathrm{CD}$ curves measured for the graphene- $\mathrm{O}_{2}: \mathrm{N}_{2}-4 \mathrm{~Pa}$ VRFB using Nafion 115 at current densities of $25,50,75$, and $100 \mathrm{~mA} \mathrm{~cm}{ }^{-2}$. (b) $\mathrm{CD}$ curves measured for the graphene- $\mathrm{O}_{2}: \mathrm{N}_{2}-4 \mathrm{~Pa}$ VRFB using Nafion XL at current densities of 100,200 , and $300 \mathrm{~mA} \mathrm{~cm}^{-2}$. (c, d) Efficiency metrics (CE, VE, and EE) of the graphene- $\mathrm{O}_{2}: \mathrm{N}_{2}-4 \mathrm{~Pa}$ VRFBs using Nafion 115 and Nafion XL extrapolated from the $\mathrm{CD}$ curve analysis as a function of the cycle number at different current densities. (e) Power density as a function of the discharge current density measured for the graphene- $\mathrm{O}_{2}: \mathrm{N}_{2}-4 \mathrm{~Pa}$ VRFB using Nafion XL. (f) Long-term stability tests of the CD performance of the graphene- $\mathrm{O}_{2}: \mathrm{N}_{2}-4 \mathrm{~Pa}$ VRFB using Nafion XL at 300 $\mathrm{mA} \mathrm{cm}{ }^{-2}$.

the rate capability of the graphene- $\mathrm{O}_{2}: \mathrm{N}_{2}-4$ Pa VRFBs using Nafion 115 and Nafion XL, respectively.

Table 1 summarizes the main efficiency metrics of the VRFBs extrapolated by the galvanostatic $\mathrm{CD}$ measurements at the investigated current densities. Clearly, Nafion XL enables the cell to efficiently operate at high power operation (i.e., current density $>100 \mathrm{~mA} \mathrm{~cm}{ }^{-2}$ ) thanks to its low resistance, which decreases the ohmic polarization losses. By benefiting from the

Table 1. Summary of the Efficiency Metrics of the Graphene$\mathrm{O}_{2}: \mathrm{N}_{2}-4$ Pa VRFBs Using Nafion 115 or Nafion $\mathrm{XL}^{a}$

$\begin{array}{ccccc}\text { Nafion } & \text { current density }\left(\mathrm{mA} \mathrm{cm}^{-2}\right) & \mathrm{CE}(\%) & \mathrm{VE}(\%) & \mathrm{EE}(\%) \\ 115 & 25 & 97.1 & 96.7 & 93.9 \\ & 50 & 97.1 & 93.4 & 90.8 \\ & 75 & 97.8 & 90.3 & 88.3 \\ \mathrm{XL} & 100 & 98.0 & 86.9 & 85.2 \\ & 100 & 97.1 & 88.2 & 85.64 \\ & 200 & 97.7 & 79.4 & 77.57 \\ & 300 & 98.8 & 70.3 & 69.45\end{array}$

${ }^{a}$ The values have been extrapolated from the galvanostatic CD measurements at various current densities and correspond to the second CD cycle. 
low resistance of Nafion XL, the graphene- $\mathrm{O}_{2}: \mathrm{N}_{2}-4$ Pa VRFB can deliver a maximum power density as high as $0.79 \mathrm{~W} \mathrm{~cm}^{-2}$ at the current density of $840 \mathrm{~mA} \mathrm{~cm}{ }^{-2}$ (Figure 6e). Meanwhile, Nafion 115 well performs at a current density $\leq 100 \mathrm{~mA} \mathrm{~cm}^{-2}$, since it limits the electrolyte cross-mixing effects typically observed in thin Nafion, ${ }^{221-223}$ guaranteeing superior CEs compared to Nafion XL.

Lastly, long-term cycling tests were performed to evaluate the durability of the proposed VRFBs. As shown in Figure 6f, graphene- $\mathrm{O}_{2}: \mathrm{N}_{2}-4 \mathrm{~Pa}$ VRFB with Nafion XL optimally operates over more than 200 cycles without significant EE changes and a slight EU decrease (ca. $-0.44 \%$ /cycle over the first 200 cycles). After such a number of cycles, the performance starts to decreases as a consequence of the anolyte losses and, thus, the change of the electrolyte composition, ${ }^{220,222,224,225}$ caused by vanadium species/water permeability through Nafion XL. These effects are consistent with the water diffusion coefficient in Nafion, ${ }^{226}$ which is between $10^{-5}$ and $10^{-6} \mathrm{~cm}^{2} \mathrm{~s}^{-1}$ (such values increase in the presence of cross-mixing of vanadium species). ${ }^{227-229}$ The electrolyte refreshing, as typically needed to extend the stability tests over thousands of $C D$ cycles, ${ }^{171,29,120,168}$ restores the initial CD performances of the cells, indicating the electrochemical and mechanical stability of the plasma-treated graphene-based electrodes. At this stage, the development of strategies to limit anolyte losses is not the scope of this work, although it represents an utmost research topic in the field of VRFBs. ${ }^{230-233}$ The exploitation of high-performant proton-exchange membranes $230,231,234,235$ is expected to further extend the cycling performance of our VRFBs.

Figure 7 shows the comparison between the EE reached by our VRFBs and those reported in relevant literature. Clearly, our

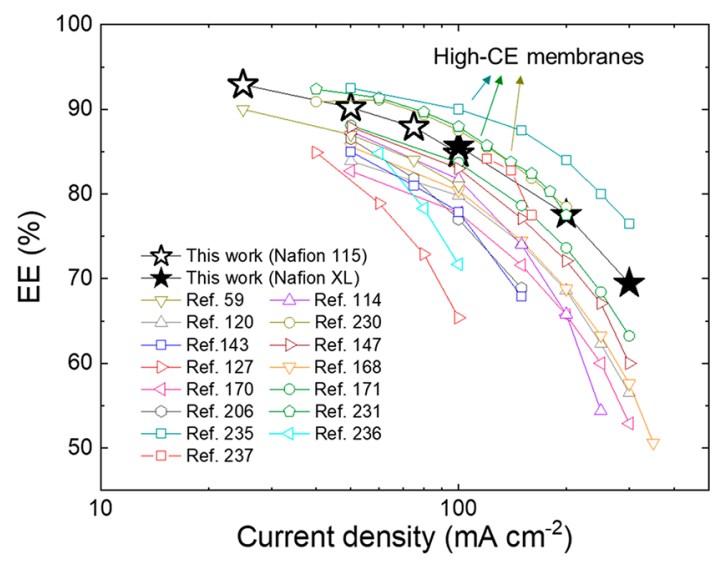

Figure 7. Comparison among the $\mathrm{CD}$ performances (EEs) of our graphene-based VRFB (graphene- $\mathrm{O}_{2}: \mathrm{N}_{2}-4 \mathrm{~Pa}$ ) and VRFBs reported in relevant literature.

VRFBs based on low-pressure combined gas plasma-treated graphene-based electrodes exhibit EEs competing with those reported in the literature at both high and low current densities. $^{230,168,120,170,156,206,231,143,171,114,59,236,147,237}$ In particular, our VRFB EEs approach those achieved using advanced high-CE $(\sim 100 \%)$ membranes, e.g., poly(ether sulfone $)^{230}$ and polybenzimidazole-based porous membranes, ${ }^{231}$ as well as thinfilm composite membranes based on an ultrathin polyamide selective layer on porous poly(ether sulfone)/sulfonated polyetheretherketone blend substrate. ${ }^{235}$ Recently, high-pressure (atmospheric) plasma was also used to treat graphite felts, increasing the electrochemical performances of the reference
VRFBs. ${ }^{237}$ Consequently, remarkable EEs of $82.8 \%, 84.2 \%$, and $77.5 \%$ were measured at the current densities of 120,140 , and $160 \mathrm{~mA} \mathrm{~cm}^{-2}$, respectively. ${ }^{237}$ Together with these results, our work remarks on the importance to study modified plasma conditions or methods to improve further the electrode performance obtained by means of the plasma treatments reported previously (including atmospheric plasmas). ${ }^{99,237}$ In particular, our low-pressure plasma treatments were effective to improve the rate capability of our VRFBs, which reached EEs as high as $85.64 \%, 77.57 \%$, and $69.45 \%$ at the current densities of 100,200 , and $300 \mathrm{~mA} \mathrm{~cm}^{-2}$, respectively. Based on our previous characterizations, low-pressure plasma with combined $\mathrm{O}_{2}$ and $\mathrm{N}_{2}$ gases is effective to provide a multiscale texturization and a chemical $\mathrm{O}$ - and $\mathrm{N}$-functionalization of our graphitic electrodes, which, thus, exhibit abundant catalytic groups for both the VRFB redox reactions. For the sake of completeness, we point out that two recent works reported by Zhao and co-workers have shown the EEs to be significantly superior to those achieved in any other system reported in the literature, reaching an EE higher than $70 \%$ at an almost incredible current density of $1 \mathrm{~A}$ $\mathrm{cm}^{-2}$ (more than twice the maximum current investigated in the most relevant literature from other research groups). ${ }^{29,76}$ These results are likely achieved thanks to an extra optimization of the system architecture beyond the design of efficient electrodes ${ }^{29,76}$ and are therefore not included in Figure 7.

\section{CONCLUSION}

We proposed a low-pressure combined gas plasma treatment in an inductively coupled radio frequency reactor to produce highly catalytic electrodes for vanadium redox flow batteries (VRFBs). The combination of multiple gases, namely, $\mathrm{O}_{2}$ and $\mathrm{N}_{2}$, in a single plasma process etches the surface of the GF fibers, while introducing both catalytic $\mathrm{O}$ and catalytic $\mathrm{N}$ functionalities. By investigating different gas plasma pressures, the electrodes were optimized to reduce their kinetic polarization toward VRFB redox reactions. The proposed low-pressure combined gas plasma treatments were further validated on hierarchical electrodes produced by decorating GF fibers with single-/few-layer graphene flakes produced through a scalable wet-jet milling exfoliation process. The optimized graphenebased VRFBs efficiently operate in a wide range of charge/ discharge (CD) current densities, from $25 \mathrm{~mA} \mathrm{~cm}^{-2}$ (energy efficiency $=93.9 \%)$ to $300 \mathrm{~mA} \mathrm{~cm}^{-2}$ (energy efficiency $\left.=69.5 \%\right)$ with optimal cycling stability over more than 200 cycles. Our VRFBs compete with the most efficient systems to date. Even more, our electrode technology has low additional costs $(<100 €$ $\mathrm{m}^{-2}$ ) compared to commercial ones, offering an industrial market-ready solution promoting the use of VRFBs for worldwide energy storage. Our work remarks on the importance to study modified plasma conditions or methods alternative to those reported previously (e.g., atmospheric plasmas) to improve further the electrode performances of the current VRFB systems. Prospectively, the use of advanced porous membranes with ultrahigh selectivity and stability could be used to boost the Coulombic efficiency of our VRFBs using Nafion membranes. In addition, the optimization of the architecture design could further decrease the kinetic losses, increasing the overall voltage efficiency during high-power density operation.

\section{EXPERIMENTAL SECTION}

5.1. Graphene Production and Characterization. The apparatus for the WJM exfoliation has been described in our recent patent $^{212}$ and studies. ${ }^{207,238}$ Additional details regarding the fabrication 
and characterization methods are reported in Supporting Information, Methods.

5.2. Formulation of the Graphene:PVDF Dispersion. The WJM-produced graphene dispersion was purified by centrifuging at $1000 \mathrm{rpm}$ for $30 \mathrm{~min}$ and collecting the supernatant. The so-produced dispersion was concentrated at $15 \mathrm{~g} \mathrm{~L}^{-1}$ by evaporating $\mathrm{N}$-methyl-2pyrrolidone with a rotovapor at $60^{\circ} \mathrm{C}$. Then, PVDF (average molecular weight $\sim 534000$, Sigma-Aldrich) was added to the SLG/FLG dispersion in a material wt $\%$ of $10 \%$.

5.3. Electrode Production and VRFB Assembly. The GF/ graphene electrodes were fabricated by infiltrating $3 \mathrm{~mL}$ of the asproduced graphene:PVDF dispersion into GFs (4.6 mm GFD, Sigracell) with an area of $5 \mathrm{~cm} \times 5 \mathrm{~cm}$. Afterward, the electrodes were dried at $150{ }^{\circ} \mathrm{C}$ under vacuum for $1 \mathrm{~h}$. Both pristine GF and GF/ graphene were treated by combined multiple gas plasma, namely, $\mathrm{O}_{2}: \mathrm{N}_{2}$ plasma with a $1: 1(\mathrm{w} / \mathrm{w})$ composition, in an inductively coupled radio frequency $(13.56 \mathrm{MHz})$ reactor at a power of $100 \mathrm{~W}$ and a process pressure ranging from 4 to $40 \mathrm{~Pa}$ (background gas pressure of $0.2 \mathrm{~Pa}$ ) for $10 \mathrm{~min}$. Single gas plasma, namely, $\mathrm{O}_{2}$ and $\mathrm{N}_{2}$ plasma, and sequential single gas plasma $\left(\mathrm{O}_{2}\right.$ plasma followed by $\mathrm{N}_{2}$ plasma, or $\mathrm{N}_{2}$ plasma followed by $\mathrm{O}_{2}$ plasma) were also investigated for comparison.

The VRFBs were assembled using a no-gap serpentine architecture (XLScribner RFB Single Cell Hardware). This hardware assembly consists of pairs of Poco Graphite flow-field layout-based graphite bipolar plates (Poco), Teflon flow frames, Viton rubber gaskets, and $\mathrm{Au}$-plated $\mathrm{Al}$ end plates with electrolyte input/output ports (Swagelok fittings). Nafion 115 (thickness of $127 \mu \mathrm{m}$ ) (Dupont) was used as the proton exchange membrane. The as-produced electrodes were inserted into the space defined by the flow frames. A compression ratio of the electrodes of $\sim 30 \%$ was defined by the thickness of both the flow frames and rubber gaskets. Peristaltic pumps (Masterflex L/S Series) were used to flow the electrolyte into the cell hardware.

5.4. Characterization of the Electrodes and VRFBs. Water contact angle measurements were obtained by using DATAPHYSICS, OCA-15 setup, and Milli-Q water drops $(2 \mu \mathrm{L})$ as the water reference. Scanning electron microscopy characterization was performed using a Helios Nanolab 600 and 450S Dual-Beam microscope (FEI Company) operating at $5 \mathrm{kV}$ and $0.2 \mathrm{nA}$. The SEM images of the electrodes were collected without any metal coating or pretreatment. X-ray photoelectron spectroscopy (XPS) analysis was carried out using a Kratos Axis Ultra ${ }^{D L D}$ spectrometer. The XPS spectra were acquired using a monochromatic $\mathrm{Al} \mathrm{K} \alpha$ source operating at $20 \mathrm{~mA}$ and $15 \mathrm{kV}$. The analysis was carried out over an area of $300 \mu \mathrm{m} \times 700 \mu \mathrm{m}$. Highresolution spectra of $\mathrm{C} 1 \mathrm{~s}, \mathrm{~N} 1 \mathrm{~s}$, and $\mathrm{O} 1 \mathrm{~s}$ regions were collected at a pass energy of $10 \mathrm{eV}$ and energy step of $0.1 \mathrm{eV}$. Energy calibration was performed setting the $\mathrm{C}-\mathrm{C}$ peak in $\mathrm{C} 1 \mathrm{~s}$ spectra at $284.8 \mathrm{eV}$. Data analysis was carried out with CasaXPS software (version 2.3.19).

Specific surface area analysis was carried out through $\mathrm{Kr}$ physisorption at $77 \mathrm{~K}^{214,215}$ in Autosorb-iQ (Quantachrome). The specific surface areas were calculated using the multipoint BET model, ${ }^{239}$ considering nine equally spaced points in a range of relative pressure $\left(P / P_{0}\right.$, where $P_{0}$ is the vapor pressure of $\mathrm{Kr}$ at $77 \mathrm{~K}$, corresponding to 2.63 Torr) between 0.10 and 0.30 .

The electrochemical measurements were performed with a potentiostat/galvanostat (VMP3, Biologic). The CV measurements of the electrodes were carried in a three-electrode cell configuration using a $\mathrm{KCl}$ saturated $\mathrm{Ag} / \mathrm{ACl}$ electrode as the reference electrode and a carbon rod as the counter electrodes. A $0.1 \mathrm{M} \mathrm{VOSO}_{4}$ (>99.9\%, Alfa Aeasar) + $3 \mathrm{M} \mathrm{H}_{2} \mathrm{SO}_{4}$ (ACS reagent, 95.0-98.0\%, Sigma-Aldrich) solution were used as the electrolyte. The VRFBs were evaluated using $1 \mathrm{M} \mathrm{VO}^{2+}+3 \mathrm{M} \mathrm{H}_{2} \mathrm{SO}_{4}$ and $1 \mathrm{M} \mathrm{V}^{3+}+3 \mathrm{M} \mathrm{H}_{2} \mathrm{SO}_{4}$ as the starting catholyte and anolyte, respectively. The electrolytes were prepared from a $1 \mathrm{MVOSO}_{4}+3 \mathrm{M} \mathrm{H}_{2} \mathrm{SO}_{4}$ solution through electrochemical method. ${ }^{240}$ The electrolytes were pumped with a flow rate of $30 \mathrm{~mL}$ $\mathrm{min}^{-1}$. Nitrogen was purged into the negative electrode reservoirs (containing $\mathrm{V}^{2+}$ and $\mathrm{V}^{3+}$ ) to avoid oxidation of $\mathrm{V}^{2+}$ when the batteries were in a charged state. The polarization curve analysis was performed on charged VRFBs. The charged state of the VRFBs was reached by applying a constant current density of $100 \mathrm{~mA} \mathrm{~cm}{ }^{-2}$ and an upper voltage limit of $1.7 \mathrm{~V}$. The VRFBs were then discharged for $30 \mathrm{~s}$ at each applied current density (ranging from 1 to $400 \mathrm{~mA} \mathrm{~cm}^{-2}$, depending on the investigated cells). Cell voltage measurements were averaged over the $30 \mathrm{~s}$ of each current step to provide a point of the polarization curve. Before acquiring the polarization curves, the high-frequency resistance of the VRFB was measured by EIS at $30 \mathrm{kHz}$, in agreement with previously reported protocols. ${ }^{79}$ The amplitude of the AC voltage perturbation was $10 \mathrm{mV}$. The $i R$ losses were calculated by the product between the applied current $(i)$ and the high-frequency resistance measured by EIS $(R)$. The $i R$-corrected polarization curves were obtained by subtracting the $i R$ losses from the raw polarization curves. The galvanostatic CD measurements of the VRFBs were carried out at different current densities (ranging from 25 to $400 \mathrm{~mA} \mathrm{~cm}^{-2}$, depending on the investigated cells). The lower and upper cell voltage limits were set to 1 and $1.6 \mathrm{~V}$, respectively.

\section{ASSOCIATED CONTENT}

\section{(s) Supporting Information}

The Supporting Information is available free of charge at https://pubs.acs.org/doi/10.1021/acs.chemmater.1c00763.

Water contact angle measurement of a plasma-treated electrode (AVI)

Additional methods, SEM, TEM, AFM, Raman spectroscopy, XPS, and electrochemical characterizations (PDF)

\section{AUTHOR INFORMATION}

\section{Corresponding Authors}

Sebastiano Bellani - BeDimensional S.p.a., 16163 Genova, Italy; Graphene Labs, Istituto Italiano di Tecnologia, 16163 Genova, Italy; Email: s.bellani@bedimensional.it

Francesco Bonaccorso - BeDimensional S.p.a., 16163 Genova, Italy; Graphene Labs, Istituto Italiano di Tecnologia, 16163 Genova, Italy; 이이이.org/0000-0001-7238-9420; Email: f.bonaccorso@bedimensional.it

\section{Authors}

Leyla Najafi - BeDimensional S.p.a., 16163 Genova, Italy; Graphene Labs, Istituto Italiano di Tecnologia, 16163 Genova, Italy

Mirko Prato - Materials Characterization Facility, Istituto Italiano di Tecnologia, 16163 Genova, Italy; (o orcid.org/ 0000-0002-2188-8059

Reinier Oropesa-Nuñez - BeDimensional S.p.a., 16163 Genova, Italy; Department of Materials Science and Engineering, Uppsala University, 75103 Uppsala, Sweden

Beatriz Martín-García - Graphene Labs, Istituto Italiano di Tecnologia, 16163 Genova, Italy; CIC nanoGUNE, 20018 Donostia-San Sebastian, Basque, Spain; (ㄱ) orcid.org/00000001-7065-856X

Luca Gagliani - Graphene Labs, Istituto Italiano di Tecnologia, 16163 Genova, Italy

Elisa Mantero - BeDimensional S.p.a., 16163 Genova, Italy; Graphene Labs, Istituto Italiano di Tecnologia, 16163 Genova, Italy

Luigi Marasco - Graphene Labs, Istituto Italiano di Tecnologia, 16163 Genova, Italy

Gabriele Bianca - Graphene Labs, Istituto Italiano di Tecnologia, 16163 Genova, Italy; Dipartimento di Chimica e Chimica Industriale, Università degli Studi di Genova, 16146 Genoa, Italy

Marilena I. Zappia - BeDimensional S.p.a., 16163 Genova, Italy; Department of Physics, University of Calabria, 87036 Rende, Cosenza, Italy

Cansunur Demirci - Dipartimento di Chimica e Chimica Industriale, Università degli Studi di Genova, 16146 Genoa, 
Italy; NanoChemistry, Istituto Italiano di Tecnologia, 16163 Genova, Italy

Silvia Olivotto - Wind Technology Innovation, Enel Global Power Generation, https://www.enel.com/

Giacomo Mariucci - Storage and New Business Design, Engineering \& Construction, Enel Green Power S.p.A., https://www.enel.com/

Vittorio Pellegrini - BeDimensional S.p.a., 16163 Genova, Italy; Graphene Labs, Istituto Italiano di Tecnologia, 16163 Genova, Italy

Massimo Schiavetti - Thermal \& Industry 4.0 Innovation, Enel Global Power Generation, https://www.enel.com/

Complete contact information is available at:

https://pubs.acs.org/10.1021/acs.chemmater.1c00763

\section{Author Contributions}

$\boldsymbol{\Delta}$ (S.B. and L.N.) These authors contributed equally.

\section{Author Contributions}

The manuscript was written through contributions of all authors.

\section{Funding}

This project has received funding from Partnership Agreement Istituto Italiano di Tecnologia and ENEL Green Power S.p.A. (prot. IIT nr. 0018079/16). This project has received funding from the European Union's Horizon 2020 research and innovation program under grant Agreement No. 785219 and No. 881603-GrapheneCore2 and GrapheneCore3, European Union's MSCA-ITN ULTIMATE project under Grant Agreement No. 813036, European Union's SENSIBAT project under Grant Agreement No. 957273, and from the Italian Ministry of Foreign Affairs and International Cooperation (MAECI) through Cooperation Project "GINGSENG" (Grant PGR05249) between Italy and China.

\section{Notes}

The authors declare no competing financial interest.

\section{ACKNOWLEDGMENTS}

We thank the Electron Microscopy facility-Istituto Italiano di Tecnologia for the support in TEM data acquisition; Dr. Andrea Toma for the access to Clean Room facilities, Istituto Italiano di Tecnologia for carrying out the SEM analysis; and Dr. Riccardo Carzino (Smart Materials group at Istituto Italiano di Tecnologia) for the contact angle measurements.

\section{ABBREVIATIONS}

$\mathrm{CD}$, charge/discharge; CE, Coulombic efficiency; CV, cyclic voltammetry; EE, energy efficiency; ESSs, energy storage systems; GFs, graphite felts; PTFE, polytetrafluoroethylene; PVDF, polyvinylidene fluoride; RFBs, redox flow batteries; SEM, scanning electron microscopy; TEM, transmission electron microscopy; VE, voltage efficiency; VRFBs, vanadium redox flow batteries; WJM, wet-jet milling; XPS, X-ray photoelectron spectroscopy

\section{REFERENCES}

(1) Luo, X.; Wang, J.; Dooner, M.; Clarke, J. Overview of Current Development in Electrical Energy Storage Technologies and the Application Potential in Power System Operation. Appl. Energy 2015, 137, 511-536.

(2) Chu, S.; Cui, Y.; Liu, N. The Path towards Sustainable Energy. Nat. Mater. 2017, 16 (1), 16-22.
(3) Larcher, D.; Tarascon, J.-M. Towards Greener and More Sustainable Batteries for Electrical Energy Storage. Nat. Chem. 2015, 7 (1), 19-29.

(4) Dunn, B.; Kamath, H.; Tarascon, J.-M. Electrical Energy Storage for the Grid: A Battery of Choices. Science (Washington, DC, U. S.) 2011, 334 (6058), 928-935.

(5) Mahlia, T. M. I.; Saktisahdan, T. J.; Jannifar, A.; Hasan, M. H.; Matseelar, H. S. C. A Review of Available Methods and Development on Energy Storage; Technology Update. Renewable Sustainable Energy Rev. 2014, 33, 532-545.

(6) Lewis, N. S. Research Opportunities to Advance Solar Energy Utilization. Science (Washington, DC, U. S.) 2016, 351 (6271), No. aad1920.

(7) Parra, D.; Norman, S. A.; Walker, G. S.; Gillott, M. Optimum Community Energy Storage for Renewable Energy and Demand Load Management. Appl. Energy 2017, 200, 358-369.

(8) Liu, M.; Steven Tay, N. H.; Bell, S.; Belusko, M.; Jacob, R.; Will, G.; Saman, W.; Bruno, F. Review on Concentrating Solar Power Plants and New Developments in High Temperature Thermal Energy Storage Technologies. Renewable Sustainable Energy Rev. 2016, 53, 1411-1432.

(9) Díaz-González, F.; Sumper, A.; Gomis-Bellmunt, O.; VillafáfilaRobles, R. A Review of Energy Storage Technologies for Wind Power Applications. Renewable Sustainable Energy Rev. 2012, 16 (4), 21542171.

(10) Denholm, P.; Ela, E.; Kirby, B.; Milligan, M. Role of Energy Storage with Renewable Electricity Generation; U.S. Department of Energy: Golden, CO, U.S.A.), 2010; DOI: 10.2172/972169.

(11) Zhao, H.; Wu, Q.; Hu, S.; Xu, H.; Rasmussen, C. N. Review of Energy Storage System for Wind Power Integration Support. Appl. Energy 2015, 137, 545-553.

(12) Lund, P. D.; Lindgren, J.; Mikkola, J.; Salpakari, J. Review of Energy System Flexibility Measures to Enable High Levels of Variable Renewable Electricity. Renewable Sustainable Energy Rev. 2015, 45, 785-807.

(13) Yekini Suberu, M.; Wazir Mustafa, M.; Bashir, N. Energy Storage Systems for Renewable Energy Power Sector Integration and Mitigation of Intermittency. Renewable Sustainable Energy Rev. 2014, 35, 499-514.

(14) Alotto, P.; Guarnieri, M.; Moro, F. Redox Flow Batteries for the Storage of Renewable Energy: A Review. Renewable Sustainable Energy Rev. 2014, 29, 325-335.

(15) Perry, M. L.; Weber, A. Z. Advanced Redox-Flow Batteries: A Perspective. J. Electrochem. Soc. 2016, 163 (1), A5064-A5067.

(16) Leung, P.; Shah, A. A.; Sanz, L.; Flox, C.; Morante, J. R.; Xu, Q.; Mohamed, M. R.; Ponce de León, C.; Walsh, F. C. Recent Developments in Organic Redox Flow Batteries: A Critical Review. J. Power Sources 2017, 360, 243-283.

(17) Winsberg, J.; Hagemann, T.; Janoschka, T.; Hager, M. D.; Schubert, U. S. Redox-Flow Batteries: From Metals to Organic RedoxActive Materials. Angew. Chem., Int. Ed. 2017, 56 (3), 686-711.

(18) Soloveichik, G. L. Flow Batteries: Current Status and Trends. Chem. Rev. 2015, 115 (20), 11533-11558.

(19) Zhang, C.; Zhang, L.; Ding, Y.; Peng, S.; Guo, X.; Zhao, Y.; He, G.; Yu, G. Progress and Prospects of Next-Generation Redox Flow Batteries. Energy Storage Mater. 2018, 15, 324-350.

(20) Ding, Y.; Zhang, C.; Zhang, L.; Zhou, Y.; Yu, G. Molecular Engineering of Organic Electroactive Materials for Redox Flow Batteries. Chem. Soc. Rev. 2018, 47 (1), 69-103.

(21) Roe, S.; Menictas, C.; Skyllas-Kazacos, M. A High Energy Density Vanadium Redox Flow Battery with $3 \mathrm{M}$ Vanadium Electrolyte. J. Electrochem. Soc. 2016, 163 (1), A5023-A5028.

(22) Janoschka, T.; Martin, N.; Hager, M. D.; Schubert, U. S. An Aqueous Redox-Flow Battery with High Capacity and Power: The TEMPTMA/MV System. Angew. Chem., Int. Ed. 2016, 55 (46), 14427-14430.

(23) Li, B.; Nie, Z.; Vijayakumar, M.; Li, G.; Liu, J.; Sprenkle, V.; Wang, W. Ambipolar Zinc-Polyiodide Electrolyte for a High-Energy Density Aqueous Redox Flow Battery. Nat. Commun. 2015, 6 (1), 6303. 
(24) Zhao, Y.; Byon, H. R. High-Performance Lithium-Iodine Flow Battery. Adv. Energy Mater. 2013, 3 (12), 1630-1635.

(25) Zhao, Y.; Wang, L.; Byon, H. R. High-Performance Rechargeable Lithium-Iodine Batteries Using Triiodide/Iodide Redox Couples in an Aqueous Cathode. Nat. Commun. 2013, 4 (1), 1896.

(26) Zhao, Y.; Ding, Y.; Li, Y.; Peng, L.; Byon, H. R.; Goodenough, J. B.; Yu, G. A Chemistry and Material Perspective on Lithium Redox Flow Batteries towards High-Density Electrical Energy Storage. Chem. Soc. Rev. 2015, 44 (22), 7968-7996.

(27) Lu, W.; Li, X.; Zhang, H. The next Generation Vanadium Flow Batteries with High Power Density - a Perspective. Phys. Chem. Chem. Phys. 2018, 20 (1), 23-35.

(28) Cheng, Y.; Wang, X.; Huang, S.; Samarakoon, W.; Xi, S.; Ji, Y.; Zhang, H.; Zhang, F.; Du, Y.; Feng, Z.; Adams, S.; Wang, Q. Redox Targeting-Based Vanadium Redox-Flow Battery. ACS Energy Lett. 2019, 4 (12), 3028-3035.

(29) Jiang, H. R.; Sun, J.; Wei, L.; Wu, M. C.; Shyy, W.; Zhao, T. S. A High Power Density and Long Cycle Life Vanadium Redox Flow Battery. Energy Storage Mater. 2020, 24, 529-540.

(30) Darling, R. M.; Gallagher, K. G.; Kowalski, J. A.; Ha, S.; Brushett, F. R. Pathways to Low-Cost Electrochemical Energy Storage: A Comparison of Aqueous and Nonaqueous Flow Batteries. Energy Environ. Sci. 2014, 7 (11), 3459-3477.

(31) Liu, T.; Wei, X.; Nie, Z.; Sprenkle, V.; Wang, W. A Total Organic Aqueous Redox Flow Battery Employing a Low Cost and Sustainable Methyl Viologen Anolyte and 4-HO-TEMPO Catholyte. Adv. Energy Mater. 2016, 6 (3), 1501449.

(32) Gong, K.; Ma, X.; Conforti, K. M.; Kuttler, K. J.; Grunewald, J. B.; Yeager, K. L.; Bazant, M. Z.; Gu, S.; Yan, Y. A Zinc-Iron Redox-Flow Battery under $\$ 100$ per KW h of System Capital Cost. Energy Environ. Sci. 2015, 8 (10), 2941-2945.

(33) Joerissen, L.; Garche, J.; Fabjan, C.; Tomazic, G. Possible Use of Vanadium Redox-Flow Batteries for Energy Storage in Small Grids and Stand-Alone Photovoltaic Systems. J. Power Sources 2004, 127 (1-2), 98-104.

(34) Yuan, Z.; Duan, Y.; Liu, T.; Zhang, H.; Li, X. Toward a Low-Cost Alkaline Zinc-Iron Flow Battery with a Polybenzimidazole Custom Membrane for Stationary Energy Storage. iScience 2018, 3, 40-49.

(35) Yang, F.; Mousavie, S. M. A.; Oh, T. K.; Yang, T.; Lu, Y.; Farley, C.; Bodnar, R. J.; Niu, L.; Qiao, R.; Li, Z. Sodium-Sulfur Flow Battery for Low-Cost Electrical Storage. Adv. Energy Mater. 2018, 8 (11), 1701991.

(36) Khor, A.; Leung, P.; Mohamed, M. R.; Flox, C.; Xu, Q.; An, L.; Wills, R. G. A.; Morante, J. R.; Shah, A. A. Review of Zinc-Based Hybrid Flow Batteries: From Fundamentals to Applications. Mater. Today Energy 2018, 8, 80-108.

(37) Gong, K.; Ma, X.; Conforti, K. M.; Kuttler, K. J.; Grunewald, J. B.; Yeager, K. L.; Bazant, M. Z.; Gu, S.; Yan, Y. A Zinc-Iron Redox-Flow Battery under $\$ 100$ per KW h of System Capital Cost. Energy Environ. Sci. 2015, 8 (10), 2941-2945

(38) Xie, C.; Duan, Y.; Xu, W.; Zhang, H.; Li, X. A Low-Cost Neutral Zinc-Iron Flow Battery with High Energy Density for Stationary Energy Storage. Angew. Chem., Int. Ed. 2017, 56 (47), 14953-14957.

(39) Noack, J.; Roznyatovskaya, N.; Herr, T.; Fischer, P. The Chemistry of Redox-Flow Batteries. Angew. Chem., Int. Ed. 2015, 54 (34), 9776-9809.

(40) Escalante Soberanis, M. A.; Mithrush, T.; Bassam, A.; Mérida, W. A Sensitivity Analysis to Determine Technical and Economic Feasibility of Energy Storage Systems Implementation: A Flow Battery Case Study. Renewable Energy 2018, 115, 547-557.

(41) Hu, B.; DeBruler, C.; Rhodes, Z.; Liu, T. L. Long-Cycling Aqueous Organic Redox Flow Battery (AORFB) toward Sustainable and Safe Energy Storage. J. Am. Chem. Soc. 2017, 139 (3), 1207-1214.

(42) Beh, E. S.; De Porcellinis, D.; Gracia, R. L.; Xia, K. T.; Gordon, R. G.; Aziz, M. J. A Neutral PH Aqueous Organic-Organometallic Redox Flow Battery with Extremely High Capacity Retention. ACS Energy Lett. 2017, 2 (3), 639-644.

(43) Li, M.-J.; Zhao, W.; Chen, X.; Tao, W.-Q. Economic Analysis of a New Class of Vanadium Redox-Flow Battery for Medium- and Large-
Scale Energy Storage in Commercial Applications with Renewable Energy. Appl. Therm. Eng. 2017, 114, 802-814.

(44) Janoschka, T.; Martin, N.; Martin, U.; Friebe, C.; Morgenstern, S.; Hiller, H.; Hager, M. D.; Schubert, U. S. An Aqueous, PolymerBased Redox-Flow Battery Using Non-Corrosive, Safe, and Low-Cost Materials. Nature 2015, 527 (7576), 78-81.

(45) Winsberg, J.; Janoschka, T.; Morgenstern, S.; Hagemann, T.; Muench, S.; Hauffman, G.; Gohy, J.-F.; Hager, M. D.; Schubert, U. S. Poly(TEMPO)/Zinc Hybrid-Flow Battery: A Novel, "Green," High Voltage, and Safe Energy Storage System. Adv. Mater. 2016, 28 (11), $2238-2243$

(46) Weber, A. Z.; Mench, M. M.; Meyers, J. P.; Ross, P. N.; Gostick, J. T.; Liu, Q. Redox Flow Batteries: A Review. J. Appl. Electrochem. 2011, 41 (10), 1137.

(47) Ponce de León, C.; Frías-Ferrer, A.; González-García, J.; Szánto, D. A.; Walsh, F. C. Redox Flow Cells for Energy Conversion. J. Power Sources 2006, 160 (1), 716-732.

(48) Zhao, P.; Zhang, H.; Zhou, H.; Chen, J.; Gao, S.; Yi, B. Characteristics and Performance of 10kW Class All-Vanadium RedoxFlow Battery Stack. J. Power Sources 2006, 162 (2), 1416-1420.

(49) Shibata, A.; Sato, K. Development of Vanadium Redox Flow Battery for Electricity Storage. Power Eng. J. 1999, 13 (3), 130-135.

(50) Turker, B.; Arroyo Klein, S.; Hammer, E.-M.; Lenz, B.; Komsiyska, L. Modeling a Vanadium Redox Flow Battery System for Large Scale Applications. Energy Convers. Manage. 2013, 66, 26-32.

(51) Xie, C.; Zhang, H.; Xu, W.; Wang, W.; Li, X. A Long Cycle Life, Self-Healing Zinc-Iodine Flow Battery with High Power Density. Angew. Chem., Int. Ed. 2018, 57 (35), 11171-11176.

(52) Weng, G.-M.; Li, Z.; Cong, G.; Zhou, Y.; Lu, Y.-C. Unlocking the Capacity of Iodide for High-Energy-Density Zinc/Polyiodide and Lithium/Polyiodide Redox Flow Batteries. Energy Environ. Sci. 2017, 10 (3), 735-741.

(53) Xie, C.; Liu, Y.; Lu, W.; Zhang, H.; Li, X. Highly Stable ZincIodine Single Flow Batteries with Super High Energy Density for Stationary Energy Storage. Energy Environ. Sci. 2019, 12 (6), 18341839.

(54) Gao, X.-P.; Yang, H.-X. Multi-Electron Reaction Materials for High Energy Density Batteries. Energy Environ. Sci. 2010, 3 (2), 174189.

(55) Chen, L.; Guo, Z.; Xia, Y.; Wang, Y. High-Voltage Aqueous Battery Approaching $3 \mathrm{~V}$ Using an Acidic-Alkaline Double Electrolyte. Chem. Commun. 2013, 49 (22), 2204-2206.

(56) Zhang, J.; Jiang, G.; Xu, P.; Ghorbani Kashkooli, A.; Mousavi, M.; $\mathrm{Yu}$, A.; Chen, Z. An All-Aqueous Redox Flow Battery with Unprecedented Energy Density. Energy Environ. Sci. 2018, 11 (8), 2010-2015.

(57) Cunha, Á.; Martins, J.; Rodrigues, N.; Brito, F. P. Vanadium Redox Flow Batteries: A Technology Review. Int. J. Energy Res. 2015, 39 (7), 889-918.

(58) Ulaganathan, M.; Aravindan, V.; Yan, Q.; Madhavi, S.; SkyllasKazacos, M.; Lim, T. M. Recent Advancements in All-Vanadium Redox Flow Batteries. Adv. Mater. Interfaces 2016, 3 (1), 1500309.

(59) Li, L.; Kim, S.; Wang, W.; Vijayakumar, M.; Nie, Z.; Chen, B.; Zhang, J.; Xia, G.; Hu, J.; Graff, G.; Liu, J.; Yang, Z. A Stable Vanadium Redox-Flow Battery with High Energy Density for Large-Scale Energy Storage. Adv. Energy Mater. 2011, 1 (3), 394-400.

(60) Lourenssen, K.; Williams, J.; Ahmadpour, F.; Clemmer, R.; Tasnim, S. Vanadium Redox Flow Batteries: A Comprehensive Review. J. Energy Storage 2019, 25, 100844.

(61) Skyllas-Kazacos, M.; Chakrabarti, M. H.; Hajimolana, S. A.; Mjalli, F. S.; Saleem, M. Progress in Flow Battery Research and Development. J. Electrochem. Soc. 2011, 158 (8), R55-R79.

(62) Hawkins, J. M. A Field Trial of a Vanadium Energy Storage System. In Twenty-Third International Telecommunications Energy Conference. INTELEC 2001; IEEE: 2001; Vol. 2001, pp 652-656.

(63) Shigematsu, T.; Kumamoto, T.; Deguchi, H.; Hara, T. Applications of a Vanadium Redox-Flow Battery to Maintain Power Quality. In IEEE/PES Transmission and Distribution Conference and Exhibition; IEEE: 2002; Vol. 2, pp 1065-1070. 
(64) Parasuraman, A.; Lim, T. M.; Menictas, C.; Skyllas-Kazacos, M. Review of Material Research and Development for Vanadium Redox Flow Battery Applications. Electrochim. Acta 2013, 101, 27-40.

(65) Skyllas-Kazacos, M.; Cao, L.; Kazacos, M.; Kausar, N.; Mousa, A. Vanadium Electrolyte Studies for the Vanadium Redox Battery-A Review. ChemSusChem 2016, 9 (13), 1521-1543.

(66) Choi, C.; Kim, S.; Kim, R.; Choi, Y.; Kim, S.; Jung, H.; Yang, J. H.; Kim, H.-T. A Review of Vanadium Electrolytes for Vanadium Redox Flow Batteries. Renewable Sustainable Energy Rev. 2017, 69, 263-274.

(67) Doetsch, C.; Burfeind, J. Vanadium Redox Flow Batteries. In Storing Energy; Elsevier: Oxford, 2016; pp 227-246.

(68) Navarro, R.; Guzman, J.; Saucedo, I.; Revilla, J.; Guibal, E. Vanadium Recovery from Oil Fly Ash by Leaching, Precipitation and Solvent Extraction Processes. Waste Manage. 2007, 27 (3), 425-438.

(69) Tsai, S.-L.; Tsai, M.-S. A Study of the Extraction of Vanadium and Nickel in Oil-Fired Fly Ash. Resour. Conserv. Recycl. 1998, 22 (3), 163176.

(70) Zhang, Y.-M.; Bao, S.-X.; Liu, T.; Chen, T.-J.; Huang, J. The Technology of Extracting Vanadium from Stone Coal in China: History, Current Status and Future Prospects. Hydrometallurgy 2011, $109(1-2), 116-124$.

(71) Moskalyk, R. R.; Alfantazi, A. M. Processing of Vanadium: A Review. Miner. Eng. 2003, 16 (9), 793-805.

(72) Yang, Z. G. Is This the Ultimate Grid Battery? IEEE Spectrum 2017, 54 (11), 36-41.

(73) Minke, C.; Kunz, U.; Turek, T. Techno-Economic Assessment of Novel Vanadium Redox Flow Batteries with Large-Area Cells. J. Power Sources 2017, 361, 105-114.

(74) Noack, J.; Wietschel, L.; Roznyatovskaya, N.; Pinkwart, K.; Tübke, J. Techno-Economic Modeling and Analysis of Redox Flow Battery Systems. Energies 2016, 9 (8), 627.

(75) Minke, C.; Turek, T. Materials, System Designs and Modelling Approaches in Techno-Economic Assessment of All-Vanadium Redox Flow Batteries - A Review. J. Power Sources 2018, 376, 66-81.

(76) Zhou, X. L.; Zeng, Y. K.; Zhu, X. B.; Wei, L.; Zhao, T. S. A HighPerformance Dual-Scale Porous Electrode for Vanadium Redox Flow Batteries. J. Power Sources 2016, 325, 329-336.

(77) Shi, Y.; Eze, C.; Xiong, B.; He, W.; Zhang, H.; Lim, T. M.; Ukil, A.; Zhao, J. Recent Development of Membrane for Vanadium Redox Flow Battery Applications: A Review. Appl. Energy 2019, 238, 202224.

(78) Chen, J.-Y.; Hsieh, C.-L.; Hsu, N.-Y.; Chou, Y.-S.; Chen, Y.-S. Determining the Limiting Current Density of Vanadium Redox Flow Batteries. Energies 2014, 7 (9), 5863-5873.

(79) Aaron, D.; Tang, Z.; Papandrew, A. B.; Zawodzinski, T. A. Polarization Curve Analysis of All-Vanadium Redox Flow Batteries. J. Appl. Electrochem. 2011, 41 (10), 1175.

(80) Aaron, D.; Sun, C.-N.; Bright, M.; Papandrew, A. B.; Mench, M. M.; Zawodzinski, T. A. In Situ Kinetics Studies in All-Vanadium Redox Flow Batteries. ECS Electrochem. Lett. 2013, 2 (3), A29-A31.

(81) Sun, C.-N.; Delnick, F. M.; Aaron, D. S.; Papandrew, A. B.; Mench, M. M.; Zawodzinski, T. A. Probing Electrode Losses in AllVanadium Redox Flow Batteries with Impedance Spectroscopy. ECS Electrochem. Lett. 2013, 2 (5), A43-A45.

(82) Cheng, D.; Li, Y.; Zhang, J.; Tian, M.; Wang, B.; He, Z.; Dai, L.; Wang, L. Recent Advances in Electrospun Carbon Fiber Electrode for Vanadium Redox Flow Battery: Properties, Structures, and Perspectives. Carbon 2020, 170, 527-542.

(83) Kim, K. J.; Park, M.-S.; Kim, Y.-J.; Kim, J. H.; Dou, S. X.; SkyllasKazacos, M. A Technology Review of Electrodes and Reaction Mechanisms in Vanadium Redox Flow Batteries. J. Mater. Chem. A 2015, 3 (33), 16913-16933.

(84) Kim, K. J.; Kim, Y.-J.; Kim, J.-H.; Park, M.-S. The Effects of Surface Modification on Carbon Felt Electrodes for Use in Vanadium Redox Flow Batteries. Mater. Chem. Phys. 2011, 131 (1-2), 547-553.

(85) Rychcik, M.; Skyllas-Kazacos, M. Characteristics of a New AllVanadium Redox Flow Battery. J. Power Sources 1988, 22 (1), 59-67.
(86) Banerjee, R.; Bevilacqua, N.; Eifert, L.; Zeis, R. Characterization of Carbon Felt Electrodes for Vanadium Redox Flow Batteries - A Pore Network Modeling Approach. J. Energy Storage 2019, 21, 163-171.

(87) Jiang, H. R.; Shyy, W.; Wu, M. C.; Zhang, R. H.; Zhao, T. S. A BiPorous Graphite Felt Electrode with Enhanced Surface Area and Catalytic Activity for Vanadium Redox Flow Batteries. Appl. Energy 2019, 233-234, 105-113.

(88) Kaneko, H.; Nozaki, K.; Wada, Y.; Aoki, T.; Negishi, A.; Kamimoto, M. Vanadium Redox Reactions and Carbon Electrodes for Vanadium Redox Flow Battery. Electrochim. Acta 1991, 36 (7), 11911196.

(89) Zhong, S.; Padeste, C.; Kazacos, M.; Skyllas-Kazacos, M. Comparison of the Physical, Chemical and Electrochemical Properties of Rayon- and Polyacrylonitrile-Based Graphite Felt Electrodes. J. Power Sources 1993, 45 (1), 29-41.

(90) González-García, J.; Bonete, P.; Expósito, E.; Montiel, V.; Aldaz, A.; Torregrosa-Maciá, R. Characterization of a Carbon Felt Electrode: Structural and Physical Properties. J. Mater. Chem. 1999, 9 (2), 419426.

(91) Oren, Y.; Soffer, A. Graphite Felt as an Efficient Porous Electrode for Impurity Removal and Recovery of Metals. Electrochim. Acta 1983, 28 (11), 1649-1654

(92) Sun, B.; Skyllas-Kazacos, M. Modification of Graphite Electrode Materials for Vanadium Redox Flow Battery Application-I. Thermal Treatment. Electrochim. Acta 1992, 37 (7), 1253-1260.

(93) Zhong, S.; Skyllas-Kazacos, M. Electrochemical Behaviour of Vanadium(V)/Vanadium(IV) Redox Couple at Graphite Electrodes. J. Power Sources 1992, 39 (1), 1-9.

(94) Zhang, W.; Xi, J.; Li, Z.; Zhou, H.; Liu, L.; Wu, Z.; Qiu, X. Electrochemical Activation of Graphite Felt Electrode for $\mathrm{VO} 2+1$ VO2+ Redox Couple Application. Electrochim. Acta 2013, 89, 429435.

(95) Sun, B.; Skyllas-Kazacos, M. Chemical Modification of Graphite Electrode Materials for Vanadium Redox Flow Battery ApplicationPart II. Acid Treatments. Electrochim. Acta 1992, 37 (13), 2459-2465.

(96) Li, X.; Huang, K.; Liu, S.; Tan, N.; Chen, L. Characteristics of Graphite Felt Electrode Electrochemically Oxidized for Vanadium Redox Battery Application. Trans. Nonferrous Met. Soc. China 2007, 17 (1), 195-199.

(97) Gao, C.; Wang, N.; Peng, S.; Liu, S.; Lei, Y.; Liang, X.; Zeng, S.; $\mathrm{Zi}, \mathrm{H}$. Influence of Fenton's Reagent Treatment on Electrochemical Properties of Graphite Felt for All Vanadium Redox Flow Battery. Electrochim. Acta 2013, 88, 193-202.

(98) Di Blasi, A.; Di Blasi, O.; Briguglio, N.; Aricò, A. S.; Sebastián, D.; Lázaro, M. J.; Monforte, G.; Antonucci, V. Investigation of Several Graphite-Based Electrodes for Vanadium Redox Flow Cell. J. Power Sources 2013, 227, 15-23.

(99) Chen, J.-Z.; Liao, W.-Y.; Hsieh, W.-Y.; Hsu, C.-C.; Chen, Y.-S. All-Vanadium Redox Flow Batteries with Graphite Felt Electrodes Treated by Atmospheric Pressure Plasma Jets. J. Power Sources 2015, 274, 894-898.

(100) Kim, K. J.; Lee, S.-W.; Yim, T.; Kim, J.-G.; Choi, J. W.; Kim, J. H.; Park, M.-S.; Kim, Y.-J. A New Strategy for Integrating Abundant Oxygen Functional Groups into Carbon Felt Electrode for Vanadium Redox Flow Batteries. Sci. Rep. 2015, 4 (1), 6906.

(101) He, Z.; Shi, L.; Shen, J.; He, Z.; Liu, S. Effects of Nitrogen Doping on the Electrochemical Performance of Graphite Felts for Vanadium Redox Flow Batteries. Int. J. Energy Res. 2015, 39 (5), 709716.

(102) Li, L.; Kim, S.; Wang, W.; Vijayakumar, M.; Nie, Z.; Chen, B.; Zhang, J.; Xia, G.; Hu, J.; Graff, G.; Liu, J.; Yang, Z. A Stable Vanadium Redox-Flow Battery with High Energy Density for Large-Scale Energy Storage. Adv. Energy Mater. 2011, 1 (3), 394-400.

(103) Shah, A. B.; Wu, Y.; Joo, Y. L. Direct Addition of Sulfur and Nitrogen Functional Groups to Graphite Felt Electrodes for Improving All-Vanadium Redox Flow Battery Performance. Electrochim. Acta 2019, 297, 905-915.

(104) Estevez, L.; Reed, D.; Nie, Z.; Schwarz, A. M.; Nandasiri, M. I.; Kizewski, J. P.; Wang, W.; Thomsen, E.; Liu, J.; Zhang, J.-G.; Sprenkle, 
V.; Li, B. Tunable Oxygen Functional Groups as Electrocatalysts on Graphite Felt Surfaces for All-Vanadium Flow Batteries. ChemSusChem 2016, 9 (12), 1455-1461.

(105) Lee, M. E.; Jin, H.-J.; Yun, Y. S. Synergistic Catalytic Effects of Oxygen and Nitrogen Functional Groups on Active Carbon Electrodes for All-Vanadium Redox Flow Batteries. RSC Adv. 2017, 7 (68), 43227-43232.

(106) Kim, K. J.; Lee, H. S.; Kim, J.; Park, M.-S.; Kim, J. H.; Kim, Y.-J.; Skyllas-Kazacos, M. Superior Electrocatalytic Activity of a Robust Carbon-Felt Electrode with Oxygen-Rich Phosphate Groups for AllVanadium Redox Flow Batteries. ChemSusChem 2016, 9 (11), 13291338

(107) He, Z.; Jiang, Y.; Zhou, H.; Cheng, G.; Meng, W.; Wang, L.; Dai, L. Graphite Felt Electrode Modified by Square Wave Potential Pulse for Vanadium Redox Flow Battery. Int. J. Energy Res. 2017, 41 (3), 439447.

(108) Lv, Y.; Li, Y.; Han, C.; Chen, J.; He, Z.; Zhu, J.; Dai, L.; Meng, W.; Wang, L. Application of Porous Biomass Carbon Materials in Vanadium Redox Flow Battery. J. Colloid Interface Sci. 2020, 566, 434443.

(109) Xu, Z.; Xiao, W.; Zhang, K.; Zhang, D.; Wei, H.; Zhang, X.; Zhang, Z.; Pu, N.; Liu, J.; Yan, C. An Advanced Integrated Electrode with Micron- and Nano-Scale Structures for Vanadium Redox Flow Battery. J. Power Sources 2020, 450, 227686.

(110) Li, C.; Xie, B.; Chen, J.; He, J.; He, Z. Enhancement of Nitrogen and Sulfur Co-Doping on the Electrocatalytic Properties of Carbon Nanotubes for VO 2+ /VO 2 + Redox Reaction. RSC Adv. 2017, 7 (22), 13184-13190.

(111) Shao, Y.; Wang, X.; Engelhard, M.; Wang, C.; Dai, S.; Liu, J.; Yang, Z.; Lin, Y. Nitrogen-Doped Mesoporous Carbon for Energy Storage in Vanadium Redox Flow Batteries. J. Power Sources 2010, 195 (13), 4375-4379.

(112) Liu, J.; Liu, S.; He, Z.; Han, H.; Chen, Y. Effects of Organic Additives with Oxygen- and Nitrogen-Containing Functional Groups on the Negative Electrolyte of Vanadium Redox Flow Battery. Electrochim. Acta 2014, 130, 314-321.

(113) Wu, T.; Huang, K.; Liu, S.; Zhuang, S.; Fang, D.; Li, S.; Lu, D.; $\mathrm{Su}, \mathrm{A}$. Hydrothermal Ammoniated Treatment of PAN-Graphite Felt for Vanadium Redox Flow Battery. J. Solid State Electrochem. 2012, 16 (2), 579-585.

(114) Huang, P.; Ling, W.; Sheng, H.; Zhou, Y.; Wu, X.; Zeng, X.-X.; Wu, X.; Guo, Y.-G. Heteroatom-Doped Electrodes for All-Vanadium Redox Flow Batteries with Ultralong Lifespan. J. Mater. Chem. A 2018, 6 (1), 41-44.

(115) Zhang, Z.; Xi, J.; Zhou, H.; Qiu, X. KOH Etched Graphite Felt with Improved Wettability and Activity for Vanadium Flow Batteries. Electrochim. Acta 2016, 218, 15-23.

(116) Park, J. J.; Park, J. H.; Park, O. O.; Yang, J. H. Highly Porous Graphenated Graphite Felt Electrodes with Catalytic Defects for HighPerformance Vanadium Redox Flow Batteries Produced via $\mathrm{NiO} / \mathrm{Ni}$ Redox Reactions. Carbon 2016, 110, 17-26.

(117) Wu, X.; Xu, H.; Shen, Y.; Xu, P.; Lu, L.; Fu, J.; Zhao, H. Treatment of Graphite Felt by Modified Hummers Method for the Positive Electrode of Vanadium Redox Flow Battery. Electrochim. Acta 2014, 138, 264-269.

(118) Chang, Y.-C.; Chen, J.-Y.; Kabtamu, D. M.; Lin, G.-Y.; Hsu, N.Y.; Chou, Y.-S.; Wei, H.-J.; Wang, C.-H. High Efficiency of CO2 -Activated Graphite Felt as Electrode for Vanadium Redox Flow Battery Application. J. Power Sources 2017, 364, 1-8.

(119) He, Z.; Jiang, Y.; Meng, W.; Jiang, F.; Zhou, H.; Li, Y.; Zhu, J.; Wang, L.; Dai, L. HF/H2O2 Treated Graphite Felt as the Positive Electrode for Vanadium Redox Flow Battery. Appl. Surf. Sci. 2017, 423, 111-118.

(120) Liu, Y.; Shen, Y.; Yu, L.; Liu, L.; Liang, F.; Qiu, X.; Xi, J. HoleyEngineered Electrodes for Advanced Vanadium Flow Batteries. Nano Energy 2018, 43, 55-62.

(121) Wang, W. H.; Wang, X. D. Investigation of Ir-Modified Carbon Felt as the Positive Electrode of an All-Vanadium Redox Flow Battery. Electrochim. Acta 2007, 52 (24), 6755-6762.
(122) Tsai, H.-M.; Yang, S.-J.; Ma, C.-C. M.; Xie, X. Preparation and Electrochemical Activities of Iridium-Decorated Graphene as the Electrode for All-Vanadium Redox Flow Batteries. Electrochim. Acta 2012, 77, 232-236.

(123) Sun, B.; Skyllas-Kazakos, M. Chemical Modification and Electrochemical Behaviour of Graphite Fibre in Acidic Vanadium Solution. Electrochim. Acta 1991, 36 (3), 513-517.

(124) Flox, C.; Rubio-Garcia, J.; Nafria, R.; Zamani, R.; Skoumal, M.; Andreu, T.; Arbiol, J.; Cabot, A.; Morante, J. R. Active Nano-CuPt3 Electrocatalyst Supported on Graphene for Enhancing Reactions at the Cathode in All-Vanadium Redox Flow Batteries. Carbon 2012, 50 (6), 2372-2374.

(125) Wei, L.; Zhao, T. S.; Zeng, L.; Zhou, X. L.; Zeng, Y. K. Copper Nanoparticle-Deposited Graphite Felt Electrodes for All Vanadium Redox Flow Batteries. Appl. Energy 2016, 180, 386-391.

(126) González, Z.; Sánchez, A.; Blanco, C.; Granda, M.; Menéndez, R.; Santamaría, R. Enhanced Performance of a Bi-Modified Graphite Felt as the Positive Electrode of a Vanadium Redox Flow Battery. Electrochem. Commun. 2011, 13 (12), 1379-1382.

(127) Li, B.; Gu, M.; Nie, Z.; Shao, Y.; Luo, Q.; Wei, X.; Li, X.; Xiao, J.; Wang, C.; Sprenkle, V.; Wang, W. Bismuth Nanoparticle Decorating Graphite Felt as a High-Performance Electrode for an All-Vanadium Redox Flow Battery. Nano Lett. 2013, 13 (3), 1330-1335.

(128) Suarez, D. J.; Gonzalez, Z.; Blanco, C.; Granda, M.; Menendez, R.; Santamaria, R. Graphite Felt Modified with Bismuth Nanoparticles as Negative Electrode in a Vanadium Redox Flow Battery. ChemSusChem 2014, 7 (3), 914-918.

(129) Li, B.; Gu, M.; Nie, Z.; Wei, X.; Wang, C.; Sprenkle, V.; Wang, W. Nanorod Niobium Oxide as Powerful Catalysts for an All Vanadium Redox Flow Battery. Nano Lett. 2014, 14 (1), 158-165.

(130) Zhou, H.; Xi, J.; Li, Z.; Zhang, Z.; Yu, L.; Liu, L.; Qiu, X.; Chen, L. CeO2 Decorated Graphite Felt as a High-Performance Electrode for Vanadium Redox Flow Batteries. RSC Adv. 2014, 4 (106), 6191261918.

(131) Jing, M.; Zhang, X.; Fan, X.; Zhao, L.; Liu, J.; Yan, C. CeO 2 Embedded Electrospun Carbon Nanofibers as the Advanced Electrode with High Effective Surface Area for Vanadium Flow Battery. Electrochim. Acta 2016, 215, 57-65.

(132) Zhou, H.; Shen, Y.; Xi, J.; Qiu, X.; Chen, L. ZrO2-NanoparticleModified Graphite Felt: Bifunctional Effects on Vanadium Flow Batteries. ACS Appl. Mater. Interfaces 2016, 8 (24), 15369-15378.

(133) He, Z.; Li, M.; Li, Y.; Li, C.; Yi, Z.; Zhu, J.; Dai, L.; Meng, W.; Zhou, H.; Wang, L. ZrO2 Nanoparticle Embedded Carbon Nanofibers by Electrospinning Technique as Advanced Negative Electrode Materials for Vanadium Redox Flow Battery. Electrochim. Acta 2019, 309, 166-176.

(134) Wu, X.; Xu, H.; Lu, L.; Zhao, H.; Fu, J.; Shen, Y.; Xu, P.; Dong, Y. PbO2-Modified Graphite Felt as the Positive Electrode for an AllVanadium Redox Flow Battery. J. Power Sources 2014, 250, 274-278. (135) Kim, K. J.; Park, M.-S.; Kim, J.-H.; Hwang, U.; Lee, N. J.; Jeong, G.; Kim, Y.-J. Novel Catalytic Effects of Mn3O4 for All Vanadium Redox Flow Batteries. Chem. Commun. 2012, 48 (44), 5455.

(136) Thu Pham, H. T.; Jo, C.; Lee, J.; Kwon, Y. MoO 2 Nanocrystals Interconnected on Mesocellular Carbon Foam as a Powerful Catalyst for Vanadium Redox Flow Battery. RSC Adv. 2016, 6 (21), 1757417582 .

(137) Bayeh, A. W.; Kabtamu, D. M.; Chang, Y.-C.; Chen, G.-C.; Chen, H.-Y.; Lin, G.-Y.; Liu, T.-R.; Wondimu, T. H.; Wang, K.-C.; Wang, C.-H. Ta2O5 -Nanoparticle-Modified Graphite Felt As a HighPerformance Electrode for a Vanadium Redox Flow Battery. ACS Sustainable Chem. Eng. 2018, 6 (3), 3019-3028.

(138) Fetyan, A.; El-Nagar, G. A.; Derr, I.; Kubella, P.; Dau, H.; Roth, C. A Neodymium Oxide Nanoparticle-Doped Carbon Felt as Promising Electrode for Vanadium Redox Flow Batteries. Electrochim. Acta 2018, 268, 59-65.

(139) Yun, N.; Park, J. J.; Park, O. O.; Lee, K. B.; Yang, J. H. Electrocatalytic Effect of $\mathrm{NiO}$ Nanoparticles Evenly Distributed on a Graphite Felt Electrode for Vanadium Redox Flow Batteries. Electrochim. Acta 2018, 278, 226-235. 
(140) Yao, C.; Zhang, H.; Liu, T.; Li, X.; Liu, Z. Carbon Paper Coated with Supported Tungsten Trioxide as Novel Electrode for AllVanadium Flow Battery. J. Power Sources 2012, 218, 455-461.

(141) Xia, L.; Long, T.; Li, W.; Zhong, F.; Ding, M.; Long, Y.; Xu, Z.; Lei, Y.; Guan, Y.; Yuan, D.; Zhang, Y.; Jia, C.; Sun, L.; Sun, Q. Highly Stable Vanadium Redox-Flow Battery Assisted by Redox-Mediated Catalysis. Small 2020, 16 (38), 2003321.

(142) Chakrabarti, M. H.; Brandon, N. P.; Hajimolana, S. A.; Tariq, F.; Yufit, V.; Hashim, M. A.; Hussain, M. A.; Low, C. T. J.; Aravind, P. V. Application of Carbon Materials in Redox Flow Batteries. J. Power Sources 2014, 253, 150-166.

(143) Park, M.; Jeon, I.-Y.; Ryu, J.; Jang, H.; Back, J.-B.; Cho, J. EdgeHalogenated Graphene Nanoplatelets with F, Cl, or Br as Electrocatalysts for All-Vanadium Redox Flow Batteries. Nano Energy 2016, 26, 233-240.

(144) Li, W.; Zhang, Z.; Tang, Y.; Bian, H.; Ng, T.; Zhang, W.; Lee, C. Graphene-Nanowall-Decorated Carbon Felt with Excellent Electrochemical Activity Toward VO $2+/ \mathrm{VO} 2+$ Couple for All Vanadium Redox Flow Battery. Adv. Sci. 2016, 3 (4), 1500276.

(145) Park, M.; Jeon, I.-Y.; Ryu, J.; Baek, J.-B.; Cho, J. Exploration of the Effective Location of Surface Oxygen Defects in Graphene-Based Electrocatalysts for All-Vanadium Redox-Flow Batteries. Adv. Energy Mater. 2015, 5 (5), 1401550.

(146) González, Z.; Flox, C.; Blanco, C.; Granda, M.; Morante, J. R.; Menéndez, R.; Santamaría, R. Outstanding Electrochemical Performance of a Graphene-Modified Graphite Felt for Vanadium Redox Flow Battery Application. J. Power Sources 2017, 338, 155-162.

(147) Deng, Q.; Huang, P.; Zhou, W.-X.; Ma, Q.; Zhou, N.; Xie, H.; Ling, W.; Zhou, C.-J.; Yin, Y.-X.; Wu, X.-W.; Lu, X.-Y.; Guo, Y.-G. A High-Performance Composite Electrode for Vanadium Redox Flow Batteries. Adv. Energy Mater. 2017, 7 (18), 1700461.

(148) Tsai, H.-M.; Yang, S.-Y.; Ma, C.-C. M.; Xie, X. Preparation and Electrochemical Properties of Graphene-Modified Electrodes for AllVanadium Redox Flow Batteries. Electroanalysis 2011, 23 (9), 21392143.

(149) Moghim, M. H.; Eqra, R.; Babaiee, M.; Zarei-Jelyani, M.; Loghavi, M. M. Role of Reduced Graphene Oxide as NanoElectrocatalyst in Carbon Felt Electrode of Vanadium Redox Flow Battery. J. Electroanal. Chem. 2017, 789, 67-75.

(150) Sankar, A.; Michos, I.; Dutta, I.; Dong, J.; Angelopoulos, A. P. Enhanced Vanadium Redox Flow Battery Performance Using Graphene Nanoplatelets to Decorate Carbon Electrodes. J. Power Sources 2018, 387, 91-100.

(151) Li, W.; Liu, J.; Yan, C. Reduced Graphene Oxide with Tunable C/O Ratio and Its Activity towards Vanadium Redox Pairs for an All Vanadium Redox Flow Battery. Carbon 2013, 55, 313-320.

(152) Hu, G.; Jing, M.; Wang, D.-W.; Sun, Z.; Xu, C.; Ren, W.; Cheng, H.-M.; Yan, C.; Fan, X.; Li, F. A Gradient Bi-Functional GrapheneBased Modified Electrode for Vanadium Redox Flow Batteries. Energy Storage Mater. 2018, 13, 66-71.

(153) Gürsu, H.; Gençten, M.; Şahin, Y. Preparation of N-Doped Graphene-Based Electrode via Electrochemical Method and Its Application in Vanadium Redox Flow Battery. Int. J. Energy Res. 2018, 42 (12), 3851-3860.

(154) Chakrabarti, B.; Nir, D.; Yufit, V.; Aravind, P. V.; Brandon, N. Enhanced Performance of an All-Vanadium Redox Flow Battery Employing Graphene Modified Carbon Paper Electrodes. Int. J. Chem. Mol. Eng. 2017, 11 (9), 622.

(155) Nia, P. M.; Abouzari-Lotf, E.; Woi, P. M.; Alias, Y.; Ting, T. M.; Ahmad, A.; Che Jusoh, N. W. Electrodeposited Reduced Graphene Oxide as a Highly Efficient and Low-Cost Electrocatalyst for Vanadium Redox Flow Batteries. Electrochim. Acta 2019, 297, 31-39.

(156) Park, M.; Jung, Y.; Kim, J.; Lee, H. il; Cho, J. Synergistic Effect of Carbon Nanofiber/Nanotube Composite Catalyst on Carbon Felt Electrode for High-Performance All-Vanadium Redox Flow Battery. Nano Lett. 2013, 13 (10), 4833-4839.

(157) Wang, S.; Zhao, X.; Cochell, T.; Manthiram, A. NitrogenDoped Carbon Nanotube/Graphite Felts as Advanced Electrode
Materials for Vanadium Redox Flow Batteries. J. Phys. Chem. Lett. 2012, 3 (16), 2164-2167.

(158) Li, W.; Liu, J.; Yan, C. Multi-Walled Carbon Nanotubes Used as an Electrode Reaction Catalyst for /VO2+ for a Vanadium Redox Flow Battery. Carbon 2011, 49 (11), 3463-3470.

(159) Li, W.; Liu, J.; Yan, C. The Electrochemical Catalytic Activity of Single-Walled Carbon Nanotubes towards VO2+/VO2+ and V3+/ V2+ Redox Pairs for an All Vanadium Redox Flow Battery. Electrochim. Acta 2012, 79, 102-108.

(160) Wei, G.; Jia, C.; Liu, J.; Yan, C. Carbon Felt Supported Carbon Nanotubes Catalysts Composite Electrode for Vanadium Redox Flow Battery applications. J. Power Sources 2012, 220, 185-192.

(161) Jelyani, M. Z.; Rashid-Nadimi, S.; Asghari, S. Treated Carbon Felt as Electrode Material in Vanadium Redox Flow Batteries: A Study of the Use of Carbon Nanotubes as Electrocatalyst. J. Solid State Electrochem. 2017, 21 (1), 69-79.

(162) He, Z.; Jiang, Y.; Li, Y.; Wang, L.; Dai, L. Boosting the Electrocatalytic Performance of Carbon Nanotubes toward V(V)/ V(IV) Reaction by Sulfonation Treatment. Int. J. Energy Res. 2018, 42 (4), 1625-1634.

(163) Chang, Y.-C.; Shih, Y.-C.; Chen, J.-Y.; Lin, G.-Y.; Hsu, N.-Y.; Chou, Y.-S.; Wang, C.-H. High Efficiency of Bamboo-like Carbon Nanotubes on Functionalized Graphite Felt as Electrode in Vanadium Redox Flow Battery. RSC Adv. 2016, 6 (104), 102068-102075.

(164) Yang, D.-S.; Lee, J. Y.; Jo, S.-W.; Yoon, S. J.; Kim, T.-H.; Hong, Y. T. Electrocatalytic Activity of Nitrogen-Doped CNT Graphite Felt Hybrid for All-Vanadium Redox Flow Batteries. Int. J. Hydrogen Energy 2018, 43 (3), 1516-1522.

(165) Li, W.; Liu, J.; Yan, C. Modified Multiwalled Carbon Nanotubes as an Electrode Reaction Catalyst for an All Vanadium Redox Flow Battery. J. Solid State Electrochem. 2013, 17 (5), 1369-1376.

(166) Etienne, M.; Vivo-Vilches, J. F.; Vakulko, I.; Genois, C.; Liu, L.; Perdicakis, M.; Hempelmann, R.; Walcarius, A. Layer-by-Layer Modification of Graphite Felt with MWCNT for Vanadium Redox Flow Battery. Electrochim. Acta 2019, 313, 131-140.

(167) He, Z.; Jiang, Y.; Wei, Y.; Zhao, C.; Jiang, F.; Li, L.; Zhou, H.; Meng, W.; Wang, L.; Dai, L. N,P Co-Doped Carbon Microsphere as Superior Electrocatalyst for VO2+/VO2+ Redox Reaction. Electrochim. Acta 2018, 259, 122-130.

(168) Zhou, Y.; Liu, L.; Shen, Y.; Wu, L.; Yu, L.; Liang, F.; Xi, J. Carbon Dots Promoted Vanadium Flow Batteries for All-Climate Energy Storage. Chem. Commun. 2017, 53 (54), 7565-7568.

(169) Wei, L.; Zhao, T. S.; Zhao, G.; An, L.; Zeng, L. A HighPerformance Carbon Nanoparticle-Decorated Graphite Felt Electrode for Vanadium Redox Flow Batteries. Appl. Energy 2016, 176, 74-79.

(170) Wu, L.; Shen, Y.; Yu, L.; Xi, J.; Qiu, X. Boosting Vanadium Flow Battery Performance by Nitrogen-Doped Carbon Nanospheres Electrocatalyst. Nano Energy 2016, 28, 19-28.

(171) Zhao, Y.; Yu, L.; Qiu, X.; Xi, J. Carbon Layer-Confined Sphere/ Fiber Hierarchical Electrodes for Efficient and Durable Vanadium Flow Batteries. J. Power Sources 2018, 402, 453-459.

(172) Maleki, M.; El-Nagar, G. A.; Bernsmeier, D.; Schneider, J.; Roth, C. Fabrication of an Efficient Vanadium Redox Flow Battery Electrode Using a Free-Standing Carbon-Loaded Electrospun Nanofibrous Composite. Sci. Rep. 2020, 10 (1), 11153.

(173) He, Z.; Cheng, G.; Jiang, Y.; Li, Y.; Zhu, J.; Meng, W.; Zhou, H.; Dai, L.; Wang, L. Novel 2D Porous Carbon Nanosheet Derived from Biomass: Ultrahigh Porosity and Excellent Performances toward V2+/ V3+ Redox Reaction for Vanadium Redox Flow Battery. Int. J. Hydrogen Energy 2020, 45 (7), 3959-3970.

(174) Abbas, S.; Lee, H.; Hwang, J.; Mehmood, A.; Shin, H.-J.; Mehboob, S.; Lee, J.-Y.; Ha, H. Y. A Novel Approach for Forming Carbon Nanorods on the Surface of Carbon Felt Electrode by Catalytic Etching for High-Performance Vanadium Redox Flow Battery. Carbon 2018, 128, 31-37.

(175) Dixon, D.; Babu, D. J.; Langner, J.; Bruns, M.; Pfaffmann, L.; Bhaskar, A.; Schneider, J. J.; Scheiba, F.; Ehrenberg, H. Effect of Oxygen Plasma Treatment on the Electrochemical Performance of the Rayon 
and Polyacrylonitrile Based Carbon Felt for the Vanadium Redox Flow Battery Application. J. Power Sources 2016, 332, 240-248.

(176) Huang, Y.; Deng, Q.; Wu, X.; Wang, S. N, O Co-Doped Carbon Felt for High-Performance All-Vanadium Redox Flow Battery. Int. J. Hydrogen Energy 2017, 42 (10), 7177-7185.

(177) O'Kane, D. F.; Mittal, K. L. Plasma Cleaning of Metal Surfaces. J. Vac. Sci. Technol. 1974, 11 (3), 567-569.

(178) Jones, C.; Sammann, E. The Effect of Low Power Plasmas on Carbon Fibre Surfaces. Carbon 1990, 28 (4), 509-514.

(179) Hammer, E.-M.; Berger, B.; Komsiyska, L. Improvement of the Performance of Graphite Felt Electrodes for Vanadium-Redox-FlowBatteries by Plasma Treatment. Int. J. Renewable Energy Dev. 2014, 3 (1), 7-12.

(180) Kimura, C.; Yamamuro, Y.; Aoki, H.; Sugino, T. Improved Field Emission Characteristics of Carbon Nanofiber Treated with Nitrogen Plasma. Diamond Relat. Mater. 2007, 16 (4-7), 1383-1387.

(181) Abbas, G.; Papakonstantinou, P.; Iyer, G. R. S.; Kirkman, I. W.; Chen, L. C. Substitutional Nitrogen Incorporation through Rf Glow Discharge Treatment and Subsequent Oxygen Uptake on Vertically Aligned Carbon Nanotubes. Phys. Rev. B: Condens. Matter Mater. Phys. 2007, 75 (19), 195429.

(182) Shao, Y.; Zhang, S.; Engelhard, M. H.; Li, G.; Shao, G.; Wang, Y.; Liu, J.; Aksay, I. A.; Lin, Y. Nitrogen-Doped Graphene and Its Electrochemical Applications. J. Mater. Chem. 2010, 20 (35), 7491.

(183) Kim, K. J.; Park, M.-S.; Kim, Y.-J.; Kim, J. H.; Dou, S. X.; SkyllasKazacos, M. A Technology Review of Electrodes and Reaction Mechanisms in Vanadium Redox Flow Batteries. J. Mater. Chem. A 2015, 3 (33), 16913-16933.

(184) Choi, C.; Noh, H.; Kim, S.; Kim, R.; Lee, J.; Heo, J.; Kim, H.-T. Understanding the Redox Reaction Mechanism of Vanadium Electrolytes in All-Vanadium Redox Flow Batteries. J. Energy Storage 2019, 21, $321-327$.

(185) Barinov, A.; Malcioğlu, O. B.; Fabris, S.; Sun, T.; Gregoratti, L.; Dalmiglio, M.; Kiskinova, M. Initial Stages of Oxidation on Graphitic Surfaces: Photoemission Study and Density Functional Theory Calculations. J. Phys. Chem. C 2009, 113 (21), 9009-9013.

(186) Yamada, Y.; Yasuda, H.; Murota, K.; Nakamura, M.; Sodesawa, T.; Sato, S. Analysis of Heat-Treated Graphite Oxide by X-Ray Photoelectron Spectroscopy. J. Mater. Sci. 2013, 48 (23), 8171-8198.

(187) Ganesan, K.; Ghosh, S.; Gopala Krishna, N.; Ilango, S.; Kamruddin, M.; Tyagi, A. K. A Comparative Study on Defect Estimation Using XPS and Raman Spectroscopy in Few Layer Nanographitic Structures. Phys. Chem. Chem. Phys. 2016, 18 (32), 22160-22167.

(188) Yue, L.; Li, W.; Sun, F.; Zhao, L.; Xing, L. Highly Hydroxylated Carbon Fibres as Electrode Materials of All-Vanadium Redox Flow Battery. Carbon 2010, 48 (11), 3079-3090.

(189) Wu, X. W.; Yamamura, T.; Ohta, S.; Zhang, Q. X.; Lv, F. C.; Liu, C. M.; Shirasaki, K.; Satoh, I.; Shikama, T.; Lu, D.; Liu, S. Q. Acceleration of the Redox Kinetics of $\mathrm{VO} 2+/ \mathrm{VO} 2+$ and V3+/V2+ Couples on Carbon Paper. J. Appl. Electrochem. 2011, 41 (10), 11831190.

(190) Lee, H. J.; Kil, D.; Kim, H. Synthesis of Activated Graphite Felt Using Consecutive Post-Treatments for Vanadium Redox Flow Batteries. J. Electrochem. Soc. 2016, 163 (13), A2586-A2591.

(191) Dixon, D.; Babu, D. J.; Bhaskar, A.; Bruns, H.-M.; Schneider, J. J.; Scheiba, F.; Ehrenberg, H. Tuning the Performance of Vanadium Redox Flow Batteries by Modifying the Structural Defects of the Carbon Felt Electrode. Beilstein J. Nanotechnol. 2019, 10, 1698-1706.

(192) Feng, J.; Guo, Z. Wettability of Graphene: From Influencing Factors and Reversible Conversions to Potential Applications. Nanoscale Horizons 2019, 4 (2), 339-364.

(193) Hong, G.; Han, Y.; Schutzius, T. M.; Wang, Y.; Pan, Y.; Hu, M.; Jie, J.; Sharma, C. S.; Müller, U.; Poulikakos, D. On the Mechanism of Hydrophilicity of Graphene. Nano Lett. 2016, 16 (7), 4447-4453.

(194) Nicholson, R. S. Theory and Application of Cyclic Voltammetry for Measurement of Electrode Reaction Kinetics. Anal. Chem. 1965, 37 (11), 1351-1355.
(195) Kissinger, P. T.; Heineman, W. R. Cyclic Voltammetry. J. Chem. Educ. 1983, 60 (9), 702.

(196) Lord, H. L.; Zhan, W.; Pawliszyn, J. Fundamentals and Applications of Needle Trap Devices. In Comprehensive Sampling and Sample Preparation; Elsevier: 2012; pp 677-697.

(197) Wu, L.; Wang, J.; Shen, Y.; Liu, L.; Xi, J. Electrochemical Evaluation Methods of Vanadium Flow Battery Electrodes. Phys. Chem. Chem. Phys. 2017, 19 (22), 14708-14717.

(198) Ma, K.; Zhang, Y.; Liu, L.; Xi, J.; Qiu, X.; Guan, T.; He, Y. In Situ Mapping of Activity Distribution and Oxygen Evolution Reaction in Vanadium Flow Batteries. Nat. Commun. 2019, 10 (1), 5286.

(199) Derr, I.; Bruns, M.; Langner, J.; Fetyan, A.; Melke, J.; Roth, C. Degradation of All-Vanadium Redox Flow Batteries (VRFB) Investigated by Electrochemical Impedance and X-Ray Photoelectron Spectroscopy: Part 2 Electrochemical Degradation. J. Power Sources 2016, 325, 351-359.

(200) Jiang, H.; Gu, J.; Zheng, X.; Liu, M.; Qiu, X.; Wang, L.; Li, W.; Chen, Z.; Ji, X.; Li, J. Defect-Rich and Ultrathin N Doped Carbon Nanosheets as Advanced Trifunctional Metal-Free Electrocatalysts for the ORR, OER and HER. Energy Environ. Sci. 2019, 12 (1), 322-333.

(201) Yang, H. B.; Miao, J.; Hung, S.-F.; Chen, J.; Tao, H. B.; Wang, X.; Zhang, L.; Chen, R.; Gao, J.; Chen, H. M.; Dai, L.; Liu, B. Identification of Catalytic Sites for Oxygen Reduction and Oxygen Evolution in N-Doped Graphene Materials: Development of Highly Efficient Metal-Free Bifunctional Electrocatalyst. Sci. Adv. 2016, 2 (4), No. e1501122.

(202) Mueller, T. R.; Adams, R. N. Voltammetry at Inert Electrodes: II. Correlation of Experimental Results with Theory for Voltage and Controlled Potential Scanning, Controlled Potential Electrolysis, and Chronopotentiometric Techniques. Oxidation of Ferrocyanide and oDianisidine at Boro. Anal. Chim. Acta 1961, 25 (5), 482-497.

(203) Huang, Y.; Liang, J.; Chen, Y. An Overview of the Applications of Graphene-Based Materials in Supercapacitors. Small 2012, 8 (12), $1805-1834$

(204) Aaron, D. S.; Liu, Q.; Tang, Z.; Grim, G. M.; Papandrew, A. B.; Turhan, A.; Zawodzinski, T. A.; Mench, M. M. Dramatic Performance Gains in Vanadium Redox Flow Batteries through Modified Cell Architecture. J. Power Sources 2012, 206, 450-453.

(205) Liu, Q. H.; Grim, G. M.; Papandrew, A. B.; Turhan, A.; Zawodzinski, T. A.; Mench, M. M. High Performance Vanadium Redox Flow Batteries with Optimized Electrode Configuration and Membrane Selection. J. Electrochem. Soc. 2012, 159 (8), A1246-A1252.

(206) Park, M.; Ryu, J.; Kim, Y.; Cho, J. Corn Protein-Derived Nitrogen-Doped Carbon Materials with Oxygen-Rich Functional Groups: A Highly Efficient Electrocatalyst for All-Vanadium Redox Flow Batteries. Energy Environ. Sci. 2014, 7 (11), 3727-3735.

(207) Del Rio Castillo, A. E.; Pellegrini, V.; Ansaldo, A.; Ricciardella, F.; Sun, H.; Marasco, L.; Buha, J.; Dang, Z.; Gagliani, L.; Lago, E.; Curreli, N.; Gentiluomo, S.; Palazon, F.; Prato, M.; Oropesa-Nuñez, R.; Toth, P. S.; Mantero, E.; Crugliano, M.; Gamucci, A.; Tomadin, A.; Polini, M.; Bonaccorso, F. High-Yield Production of 2D Crystals by Wet-Jet Milling. Mater. Horiz. 2018, 5 (5), 890-904.

(208) Bellani, S.; Martín-García, B.; Oropesa-Nuñez, R.; Romano, V.; Najafi, L.; Demirci, C.; Prato, M.; Del Rio Castillo, A. E.; Marasco, L.; Mantero, E.; D'Angelo, G.; Bonaccorso, F. Ion Sliding” on Graphene: A Novel Concept to Boost Supercapacitor Performance. Nanoscale Horizons 2019, 4 (5), 1077-1091.

(209) Garakani, M. A.; Bellani, S.; Pellegrini, V.; Oropesa-Nuñez, R.; Castillo, A. E. D. R.; Abouali, S.; Najafi, L.; Martín-García, B.; Ansaldo, A.; Bondavalli, P.; Demirci, C.; Romano, V.; Mantero, E.; Marasco, L.; Prato, M.; Bracciale, G.; Bonaccorso, F. Scalable Spray-Coated Graphene-Based Electrodes for High-Power Electrochemical DoubleLayer Capacitors Operating over a Wide Range of Temperature. Energy Storage Mater. 2021, 34, 1-11.

(210) Bellani, S.; Wang, F.; Longoni, G.; Najafi, L.; Oropesa-Nuñez, R.; Del Rio Castillo, A. E.; Prato, M.; Zhuang, X.; Pellegrini, V.; Feng, X.; Bonaccorso, F. WS 2 -Graphite Dual-Ion Batteries. Nano Lett. 2018, 18 (11), 7155-7164. 
(211) Romano, V.; Martín-García, B.; Bellani, S.; Marasco, L.; Kumar Panda, J.; Oropesa-Nuñez, R.; Najafi, L.; Del Rio Castillo, A. E.; Prato, M.; Mantero, E.; Pellegrini, V.; D’Angelo, G.; Bonaccorso, F. Flexible Graphene/Carbon Nanotube Electrochemical Double-Layer Capacitors with Ultrahigh Areal Performance. ChemPlusChem 2019, 84 (7), 882-892.

(212) Del Rio Castillo, A. E.; Ansaldo, A.; Pellegrini, V.; Bonaccorso, F. Exfoliation of Layered Materials by Wet Jet Milling Techniques. WO 2017/089987 A1, 2017.

(213) Gamucci, A.; Pellegrini, V.; Bonaccorso, F. Dispositivo Di Protezione Corporale, Particolarmente Casco Protettivo. PCT 1B2017/056241, 2017.

(214) Fagerlund, G. Determination of Specific Surface by the BET Method. Mater. Constr. 1973, 6 (3), 239-245.

(215) Walton, K. S.; Snurr, R. Q. Applicability of the BET Method for Determining Surface Areas of Microporous Metal-Organic Frameworks. J. Am. Chem. Soc. 2007, 129 (27), 8552-8556.

(216) Han, P.; Yue, Y.; Liu, Z.; Xu, W.; Zhang, L.; Xu, H.; Dong, S.; Cui, G. Graphene Oxide Nanosheets/Multi-Walled Carbon Nanotubes Hybrid as an Excellent Electrocatalytic Material towards VO2+/VO2+ Redox Couples for Vanadium Redox Flow Batteries. Energy Environ. Sci. 2011, 4 (11), 4710.

(217) González, Z.; Botas, C.; Blanco, C.; Santamaría, R.; Granda, M.; Álvarez, P.; Menéndez, R. Thermally Reduced Graphite and Graphene Oxides in VRFBs. Nano Energy 2013, 2 (6), 1322-1328.

(218) Shi, S.; Weber, A. Z.; Kusoglu, A. Structure/Property Relationship of Nafion XL Composite Membranes. J. Membr. Sci. 2016, 516, 123-134.

(219) Rodgers, M. P.; Bonville, L. J.; Mukundan, R.; Borup, R. L.; Ahluwalia, R.; Beattie, P.; Brooker, R. P.; Mohajeri, N.; Kunz, H. R.; Slattery, D. K.; Fenton, J. M. Perfluorinated Sulfonic Acid Membrane and Membrane Electrode Assembly Degradation Correlating Accelerated Stress Testing and Lifetime Testing. ECS Trans. 2013, 58 (1), 129-148.

(220) Yu, L.; Lin, F.; Xu, L.; Xi, J. Structure-Property Relationship Study of Nafion XL Membrane for High-Rate, Long-Lifespan, and AllClimate Vanadium Flow Batteries. RSC Adv. 2017, 7 (50), 3116431172 .

(221) Jiang, B.; Wu, L.; Yu, L.; Qiu, X.; Xi, J. A Comparative Study of Nafion Series Membranes for Vanadium Redox Flow Batteries. J. Membr. Sci. 2016, 510, 18-26.

(222) Jiang, B.; Yu, L.; Wu, L.; Mu, D.; Liu, L.; Xi, J.; Qiu, X. Insights into the Impact of the Nafion Membrane Pretreatment Process on Vanadium Flow Battery Performance. ACS Appl. Mater. Interfaces 2016, 8 (19), 12228-12238.

(223) Darling, R. M.; Weber, A. Z.; Tucker, M. C.; Perry, M. L. The Influence of Electric Field on Crossover in Redox-Flow Batteries. J. Electrochem. Soc. 2016, 163 (1), A5014-A5022.

(224) Majsztrik, P.; Bocarsly, A.; Benziger, J. Water Permeation through Nafion Membranes: The Role of Water Activity. J. Phys. Chem. B 2008, 112 (51), 16280-16289.

(225) Duan, Q.; Wang, H.; Benziger, J. Transport of Liquid Water through Nafion Membranes. J. Membr. Sci. 2012, 392-393, 88-94.

(226) Zhao, Q.; Majsztrik, P.; Benziger, J. Diffusion and Interfacial Transport of Water in Nafion. J. Phys. Chem. B 2011, 115 (12), 27172727.

(227) Mu, D.; Zhao, Y.; Yu, L.; Liu, L.; Xi, J. Asymmetric Vanadium Flow Batteries: Long Lifespan via an Anolyte Overhang Strategy. Phys. Chem. Chem. Phys. 2017, 19 (43), 29195-29203.

(228) Wang, K.; Liu, L.; Xi, J.; Wu, Z.; Qiu, X. Reduction of Capacity Decay in Vanadium Flow Batteries by an Electrolyte-Reflow Method. J. Power Sources 2017, 338, 17-25.

(229) Park, J. H.; Park, J. J.; Park, O. O.; Yang, J. H. Capacity Decay Mitigation by Asymmetric Positive/Negative Electrolyte Volumes in Vanadium Redox Flow Batteries. ChemSusChem 2016, 9 (22), 31813187.

(230) Lu, W.; Yuan, Z.; Zhao, Y.; Li, X.; Zhang, H.; Vankelecom, I. F. J. High-Performance Porous Uncharged Membranes for Vanadium
Flow Battery Applications Created by Tuning Cohesive and Swelling Forces. Energy Environ. Sci. 2016, 9 (7), 2319-2325.

(231) Yuan, Z.; Duan, Y.; Zhang, H.; Li, X.; Zhang, H.; Vankelecom, I. Advanced Porous Membranes with Ultra-High Selectivity and Stability for Vanadium Flow Batteries. Energy Environ. Sci. 2016, 9 (2), 441447.

(232) Wei, L.; Fan, X. Z.; Jiang, H. R.; Liu, K.; Wu, M. C.; Zhao, T. S. Enhanced Cycle Life of Vanadium Redox Flow Battery via a Capacity and Energy Efficiency Recovery Method. J. Power Sources 2020, 478, 228725.

(233) Li, Z.; Liu, L.; Zhao, Y.; Xi, J.; Wu, Z.; Qiu, X. The Indefinite Cycle Life via a Method of Mixing and Online Electrolysis for Vanadium Redox Flow Batteries. J. Power Sources 2019, 438, 226990.

(234) Kim, J. Q.; So, S.; Kim, H.-T.; Choi, S. Q. Highly Ordered Ultrathin Perfluorinated Sulfonic Acid Ionomer Membranes for Vanadium Redox Flow Battery. ACS Energy Lett. 2021, 6 (1), 184-192.

(235) Dai, Q.; Liu, Z.; Huang, L.; Wang, C.; Zhao, Y.; Fu, Q.; Zheng, A.; Zhang, H.; Li, X. Thin-Film Composite Membrane Breaking the Trade-off between Conductivity and Selectivity for a Flow Battery. Nat. Commun. 2020, 11 (1), 13.

(236) Zhao, C.; Li, Y.; He, Z.; Jiang, Y.; Li, L.; Jiang, F.; Zhou, H.; Zhu, J.; Meng, W.; Wang, L.; Dai, L. KHCO3 Activated Carbon Microsphere as Excellent Electrocatalyst for $\mathrm{VO} 2+/ \mathrm{VO} 2+$ Redox Couple for Vanadium Redox Flow Battery. J. Energy Chem. 2019, 29, 103-110.

(237) Lin, C. H.; Zhuang, Y. D.; Tsai, D. G.; Wei, H. J.; Liu, T. Y. Polymers 2020, 12, 1372.

(238) Lamanna, E.; Matteocci, F.; Calabrò, E.; Serenelli, L.; Salza, E.; Martini, L.; Menchini, F.; Izzi, M.; Agresti, A.; Pescetelli, S.; Bellani, S.; Del Río Castillo, A. E.; Bonaccorso, F.; Tucci, M.; Di Carlo, A. Mechanically Stacked, Two-Terminal Graphene-Based Perovskite/ Silicon Tandem Solar Cell with Efficiency over 26\%. Joule 2020, 4 (4), 865-881.

(239) Brunauer, S.; Emmett, P. H.; Teller, E. Adsorption of Gases in Multimolecular Layers. J. Am. Chem. Soc. 1938, 60 (2), 309-319.

(240) Li, W.; Zaffou, R.; Sholvin, C. C.; Perry, M. L.; She, Y. Vanadium Redox-Flow-Battery Electrolyte Preparation with Reducing Agents. ECS Trans. 2013, 53 (7), 93-99. 